\title{
Effect of explicit urban land surface representation on the simulation of the 26 July 2005 heavy rain event over Mumbai, India
}

\author{
M. Lei ${ }^{1}$, D. Niyogi ${ }^{1}$, C. Kishtawal ${ }^{2}$, R. A. Pielke, Sr. ${ }^{3}$, A. Beltrán-Przekurat ${ }^{3}$, T. E. Nobis ${ }^{3}$, and S. S. Vaidya ${ }^{4}$ \\ ${ }^{1}$ Purdue University, Department of Earth and Atmospheric Sciences and Department of Agronomy, \\ West Lafayette, IN 47906, USA \\ ${ }^{2}$ SAC/ISRO, Ahmedabad 380015, India \\ ${ }^{3}$ University of Colorado at Boulder, CIRES, Boulder, CO 80309, USA \\ ${ }^{4}$ Indian Institute of Tropical Meteorology, Homi Bhabha Road, Pune 411008, India
}

Received: 3 January 2008 - Published in Atmos. Chem. Phys. Discuss.: 16 May 2008

Revised: 11 August 2008 - Accepted: 19 August 2008 - Published: 16 October 2008

\begin{abstract}
We investigate whether explicit representation of the urban land surface improves the simulation of the recordbreaking 24-h heavy rain event that occurred over Mumbai, India on 26 July 2005 as the event has been poorly simulated by operational weather forecasting models. We conducted experiments using the Regional Atmosphere modeling system (RAMS 4.3), coupled with and without explicit urban energy balance model-town energy budget (TEB) to study the role of urban land - atmosphere interactions in modulating the heavy rain event over the Indian monsoon region. The impact of including an explicit urban energy balance on surface thermodynamic, boundary layer, and circulation changes are analyzed. The results indicate that even for this synoptically active rainfall event, the vertical wind and precipitation are significantly influenced by heterogeneity in surface temperatures due to urbanization, and the effect is more significant during the storm initiation. Interestingly, precipitation in the upwind region of Mumbai city is increased in the simulation, possibly as a feedback from the sea breeze - urban landscape convergence. We find that even with the active monsoon, the representation of urbanization contributes to local heavy precipitation and mesoscale precipitation distribution over the Indian monsoon region. Additional experiments within a statistical dynamical framework show that an urban model by itself is not the dominant factor for the enhanced rainfall for a Mumbai heavy rain event; the combination of updated SST fields using Tropical Rainfall Measurement Mission (TRMM) data with the detailed representation of urban effects simulated by the TEB model created realistic gradients that successfully maintained the
\end{abstract}

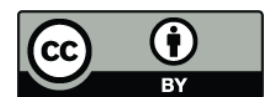

Correspondence to: D. Niyogi (climate@purdue.edu) convergence zone over Mumbai. Further research will require more detailed morphology data for simulating weather events in such urban regions. The results suggest that urbanization can significantly contribute to extremes in monsoonal rain events that have been reported to be on the rise.

\section{Introduction}

On 26 July 2005, an unexpected heavy precipitation event occurred over the Mumbai urban region and adjacent areas. A steady downpour initiated around 11:00 a.m. local time (06:00 UTC), and several regions within a $100 \mathrm{~km}$ area showed an unprecedented amount of rainfall over the following 24-h period. For instance, the Santacruz India Meteorological Department (IMD) official rainfall data recorded a record-breaking $944 \mathrm{~mm}$ 24-h rainfall total. Storm reports recorded locations in north Mumbai that received around $1000 \mathrm{~mm}$ of rainfall. The event also showed remarkable variability between locations, with stations in southern Mumbai receiving from a trace to $\sim 74 \mathrm{~mm}$ of rain at another IMD rainfall gauge at Colaba ( $25 \mathrm{~km}$ south of Santacruz). The event caused nearly 500 deaths and is classified as a billion US Dollars natural disaster (NCDC, 2007).

Most forecasting models did not successfully predict this heavy rain event. This event is being studied by a number of forecasting groups and teams to improve model performance and subsequently, forecast accuracy. Chang et al. (2008) used a MM5 and WRF model to simulate this event and found that the MM5 could reproduce about $40-60 \%$ of the Mumbai rainfall, while the WRF simulated about $60-80 \%$ of the observed precipitation. Bohra et al. (2006) documented the India National Center for Medium Range Weather Forecasting

Published by Copernicus Publications on behalf of the European Geosciences Union. 
(NCMWRF) synthesis of this heavy rain event. They concluded that a high resolution model setup could significantly enhance model performance but most of the predicted rain was in the range of 100-200 mm. Jenamani et al. (2006) studied the IMD analysis of the Mumbai rain event, and they found that the rain band/low pressure system positioned over the Western Ghats interacted with mesoscale processes to create the heavy rain event. Vaidya and Kulkarni (2006) independently confirmed a similar conclusion; and found that a cloud burst phenomenon was the main reason for the heavy rain. They also concluded that the event could be reasonably simulated using a high resolution mesoscale model with a proper choice of boundary conditions and domain size (to capture the synoptic and mesoscale feedbacks). Shyamala and Bhadram (2006) extended the analysis using observational data for synoptic, thermodynamic, radar, and satellite analyses. They concluded that a cloud band over the Arabian Sea on 25 July corresponded to a strong low-level wind over Mumbai, and that mid-troposphere dryness might have contributed to the heavy rain. Chang et al. (2008) tested the impact of land surface representation within the Weather Research and Forecasting (WRF) modelling system; and concluded that the results were sensitive to the choice of convection parameterizations and land-surface processes.

Global climate model ensemble experiments by Koster et al. (2004) highlighted the Indian monsoon region as a landatmosphere coupling "hotspot." Goswami et al. (2006) analyzed the rainfall patterns over the Indian monsoon region and concluded that the heavy rain events are significantly increasing. Kishtawal et al. (2008) ${ }^{1}$ analyzed the long-term rainfall data and found urban regions have more statistically significant precipitation occurrence as compared to the rural regions. Studies such as Braham and Wilson (1978), Shepherd and Burian (2003), and Niyogi et al. (2006) have shown urban land surface can influence local storm structure causing enhanced convection and increased precipitation. The role of urban landscape on the heavy rain simulation over the synoptically active Indian monsoon region has not been studied.

The impact of urban land surface on regional meteorology is well documented. Studying the surface temperature patterns, Howard (1833) delineated the urban heat island (UHI) in London. Subsequently, a number of studies have found that the urban heat island is an important feature in regional meteorology (Oke, 1988). In recent decades, interest has grown in the impact of urbanization on mesoscale convection and precipitation. Urban landscapes have been linked to the initiation or intensification of convective activities over cities through altered thermodynamic stability. Niyogi et al. (2006) studied urban-rural heterogeneity-based convective boundaries which affected precipitation patterns around

\footnotetext{
${ }^{1}$ Kishtawal, C., Niyogi, D., Tewari, M., Pielke, Sr., R. A., and Shepherd, M.: Heavy Rainfall During Indian Summer Monsoon: A Clear Urban Bias, Int. J. Climatol., in revision, 2008.
}

Oklahoma City. Shepherd et al. (2002) found more intense rainfall rates over and downwind of major cities such as Atlanta and Dallas. Rozoff et al. (2003) found that the UHI during a thunderstorm event over St. Louis, Missouri had the largest role in initiating deep, moist convection downwind of the city. Therefore the urban energy balance is vital to the understanding of the importance of meteorological variables within urban areas. Gero and Pitman (2006) studied the storm climatology in Australia's Sydney Basin and found that the local convective storms were highly sensitive to the triggering mechanism associated with land surface influences. Pyle et al. (2008) analyzed the Indianapolis urban region and its storm climatology and concluded that urban land surface can change storm morphology and regional precipitation. Thus, significant background evidence suggests that the urban landscape can affect storm morphology, and that mesoscale boundaries can modify storm-related precipitation.

Mumbai is a major coastal city on the west coast of India and is the country's commercial capital. The population of the downtown and surrounding suburbs increased from 9.9 million in 1981 to 13.0 million in 1991 and 17.7 million in 2001 (International Institute for Population Studies, IIPS). The city is experiencing rapid urbanization, and such densely populated cities with an aging infrastructure are very vulnerable to natural disasters. Therefore, it is important to assess the possible impact of the Mumbai urban landscape and its representation in the July 2005 heavy rain event.

To date, the 26 July 2005 heavy rain event in Mumbai has many clear features, yet many unknown causes, thus we are primarily interested in clarifying the role that landscape change including urbanization played in this event. Our hypotheses include:

1. By using an explicit 3-D urban surface energy balance model - Town Energy Budget (TEB), we can better represent the land - atmospheric interactions and improve the simulation of the heavy rain event over Mumbai city in a mesoscale model;

2. Precipitation distribution and intensity will be significantly changed due to the urban landscape, especially in upwind and downwind regions;

3. The effect of urbanization on heavy precipitation occurs on a relatively local scale near the urban region, and the large-scale precipitation will be influenced by the sea surface temperature (SST) fields.

\section{Data and methodology}

The Regional Atmospheric Modeling System (RAMS) version 4.3 (Pielke et al., 1992, 2001; Cotton et al., 2003) was adopted for this study. RAMS is a primitive equation, non-hydrostatic mesoscale environmental modeling system; 
Table 1. Basic model configuration.

\begin{tabular}{ll}
\hline Category & Options \\
\hline Governing equations & 3-D, non hydrostatic, compressible \\
Vertical coordinate & Terrain-following $\delta z$ \\
Grid stagger and configuration & Arakawa-C grid; three fixed, nested grids \\
Time differentiation & Leapfrog and forward time difference \\
Turbulence closure & Kfrom deformation scaled by stability \\
Lower boundary and urban surface & LEAF-2 with TEB (For Domain 4) \\
Upper boundary & Rigid lid with modified Rayleigh friction layer \\
Lateral boundaries & Klemp and Wilhelmson (1978) \\
Microphysics & Single-moment bulk microphysics \\
Cumulus parameterization & Modified Kuo - Tremback (1990) \\
Radiation & Chen and cotton (1983) \\
\hline
\end{tabular}

its performance to skilfully simulate convective systems has been validated in various prior studies (e.g. Nair et al., 1997; Rozoff et al., 2003), including a study over India (Mukhopadhyay et al., 2005).

RAMS involves a two-way interactive grid nesting. The three nested grids in this study had an 80,20 , and $5 \mathrm{~km}$ grid spacing with the same center points $(19.15 \mathrm{~N}, 73.05 \mathrm{E})$ as shown in Fig. 1. Grid 1 had $36 \times 26$ horizontal grid points and a time step of $27 \mathrm{~s}$ that covers the whole south Asian monsoon region. The second domain simulated the general synoptic and mesoscale setting with $82 \times 74$ horizontal grid points and a time step of $9 \mathrm{~s}$. The third grid has $94 \times 58$ horizontal grid points, and a time step of $3 \mathrm{~s}$. The grid was mostly focused over Mumbai and its adjacent Arabian Sea region. We selected 36 vertical layers with spacing from 0.05 to $1.27 \mathrm{~km}$ in the first $8.5 \mathrm{~km}$ of the atmosphere; the spacing was maintained at $1.27 \mathrm{~km}$ for heights above $8.5 \mathrm{~km}$. The total depth of the model atmosphere is $15 \mathrm{~km}$. The urban model was coupled to RAMS over the innermost region which covers Mumbai.

Model initialization for this study was horizontally inhomogeneous with forcing data from the National Center for Environmental Prediction (NCEP) Global Data Assimilation System (GDAS) (Kalnay et al., 1996). All simulations were performed for $120 \mathrm{~h}$ from 25-30 July 2005. Soil moisture was initialized at $35 \%$ of soil moisture capacity (as a percentage of soil texture dependent saturation) and followed the GDAS fields. The soil moisture and soil temperature quickly produced spatial heterogeneity in the region. This study used the modified Kuo cumulus parameterization scheme for domain 1 and 2. Table 1 summarizes the basic model configuration.

A number of model experiments were performed and the most significant impact was found for prescription of SST fields. SST was important for setting the mesoscale boundaries in the coastal regions. We used the default SST data in RAMS 4.3 as the climatological SST from 1950 to 1980

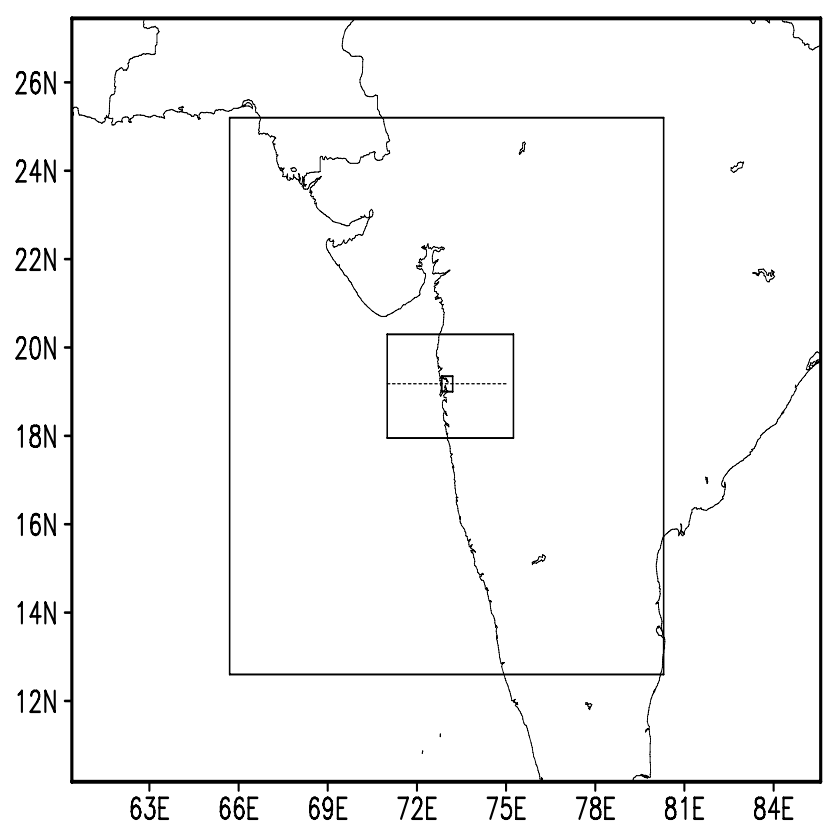

Fig. 1. Simulation model domains and idealized urban region over Mumbai city (inner most domain with TEB). Dashed line in third domain indicates the cross-section (at $19.15 \mathrm{~N}$ ) analyzed in this study.

for the sensitivity study discussed below. The model results discussed in the following section, however, utilize Tropical Rainfall Measurement Mission (TRMM) Microwave Imager (TMI) SST data. The weekly data from 23 July (0.25 degree resolution) is used. The TRMM satellite travels west to east in a semi-equatorial orbit. This path produced data collected at changing local times for any given earth location between latitudes $40^{\circ} \mathrm{S}$ and $40^{\circ} \mathrm{N}$. As compared to the climatology, the TRMM data shows a higher SST and a larger gradient along the Western Ghats (Fig. 2a-b). Figure 2b shows a high 
Table 2a. Key variables value input for TEB. Average values of variables for the city.

\begin{tabular}{ll}
\hline Key variables & Value (average) \\
\hline Urban Building height $(\mathrm{m})$ & 8 \\
Building width $(\mathrm{m})$ & 3 \\
$\mathrm{z}_{0}(\mathrm{~m})$ & 0.8 \\
Traffic sensible heat release $\left(\mathrm{Wm}^{-2}\right)$ & 12 \\
Traffic latent heat source $\left(\mathrm{Wm}^{-2}\right)$ & 0 \\
Industrial sensible heat source $\left(\mathrm{Wm}^{-2}\right)$ & 20 \\
Industrial latent heat source $\left(\mathrm{Wm}^{-2}\right)$ & 10 \\
Constant temperature inside building $(\mathrm{K})$ & 300 \\
\hline
\end{tabular}

SST zone $(305 \mathrm{~K})$ near the west coast of Mumbai which is noteworthy, as is shown in the model simulations.

The default land surface model-Land Ecosystem Atmosphere Feedback (LEAF-2) model (Walko et al., 2000) was used to account for the exchange of heat and moisture between the soil, vegetation, canopy, surface water, and atmosphere. LEAF-2 explicitly represents canopy processes following Deardorff (1978). It also represents the details of turbulent exchange and radiative transfer, as well as physical evaporation, transpiration, precipitation, and fluxes of heat and moisture between the soil or snow and the atmosphere (Lee, 1992; Walko et al., 2000). LEAF2 vegetation types comprise a combination of Biosphere Atmosphere Transfer Scheme (BATS) and land data assimilation system (LDAS) classes (Dickinson, 1984). The land-use data are based on the USGS global data set at $30 \mathrm{~s}(\sim 1 \mathrm{~km})$ spatial grid increment (Pielke et al., 1997).

For the innermost domain, the LEAF2 scheme was coupled with an explicit urban model: the Town Energy Budget (Masson, 2000) to study the urban area (only LEAF2 run is considered as control run). The TEB is used only for energy balance over the urban land use grids, while LEAF2 is the default. The $5 \mathrm{~km}$ grid spacing in the third domain was further allowed to have 4 subgrid land-use categories following a mosaic approach (Avissar and Pielke, 1989; Koster and Suarez, 1996). For the urban subgrid land use, the TEB was used for solving the energy budget, and for other land uses, the default LEAF2 representations were employed. The total (grid-averaged) fluxes and scalar output for the grids with urban land use thus consisted of a sum of the TEB and LEAF2.

For the TEB, information on the buildings, roads and average geometry of the urban area are needed. We constructed the TEB parameters for Mumbai city based on our knowledge of local geography and discussions with local experts; the final land-use morphology domain was also guided by several high resolution (street scale) maps including Google Earth maps (maps.google.com). Typically for downtown areas, the grid average building height was specified as $8 \mathrm{~m}$, with varying building and canyon ratios. The roughness length was approximated as $0.8 \mathrm{~m}$ (or $10 \%$ of the building height). Table 2 summarizes important TEB parameters. These data were based on our knowledge of the model domain and studies reported in Oke (1988), Johnson et al. (1991), Masson (2000) and Rozoff et al. (2003). We stress that the table created was principally for driving the model and had a high degree of approximation. We also highlight the need for publicly available urban morphology data for urban models.

\section{Results}

\subsection{Synoptic scenario}

In July 2005 when the monsoon was active, strong westerly or southwesterly wind flow developed along with the formation of an offshore trough over the Arabian Sea (Kumar et al., 2008). A low-pressure system formed over the North Bay of Bengal and Orissa coast on 24 July and intensified as it moved inland. It brought the monsoon trough to the south of its average position along 20-22 N, with a strong cross-equatorial flow over the Arabian Sea. As the system moved westward, the low-level jet continuously intensified, and strong westerly winds lashed the west coasts. Generally, this scenario leads to widespread heavy rainfall over the Western Ghats and Mumbai regions (Francis and Gadgil, 2006; Kumar et al., 2007). On 26 July, the rain belt dropped more than $100 \mathrm{~mm}$ of precipitation at many stations in Konkan (Western Ghats) and Goa and then moved northward. Subsequently on the 26 July, Mumbai and many other parts of Maharashtra (east of Mumbai) were devastated with heavy rains.

Both the lower- and upper-level large-scale flow patterns over the Indian region can be viewed using the $850 \mathrm{hPa}$ and $300 \mathrm{hPa}$ wind analysis from the NCEP analyses valid at $12 \mathrm{Z}$ 26 July 2005 from the NCEP analyses (Fig. 3). Figure 3a shows the presence of a strong cyclonic circulation that extends upwards to the mid-troposphere over Orissa and eastern part of Madhya Pradesh associated with a well-marked low-pressure system near the surface. The $850 \mathrm{hPa}$ plots also show the presence of strong westerly or north-westerly winds with speeds of $20 \mathrm{~m} \mathrm{~s}^{-1}$ (Fig. 3a) over the western coast of India including Mumbai. This low-level, strong westerly or northwesterly wind became easterly or northeasterly at $300 \mathrm{hPa}$ (Fig. 3b) with speeds between $6-12 \mathrm{~m} \mathrm{~s}^{-1}$ over Mumbai. Model simulations shown in Fig. 3c-d, successfully captured both features remarkably well.

The divergence components of the wind provide an understanding of the atmospheric divergent circulation associated with the vertical motion field. Generally the atmospheric heating associated with convection will induce centers of divergence. Analysis of the divergence field (Fig. 4a-d) at various times on 26 July 2005 indicate that the upper-level divergence, overlying deep low- and mid-level convergence had 


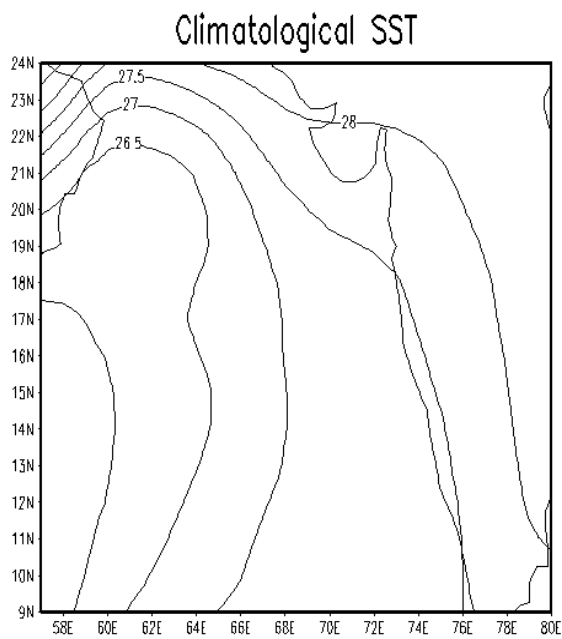

(a)

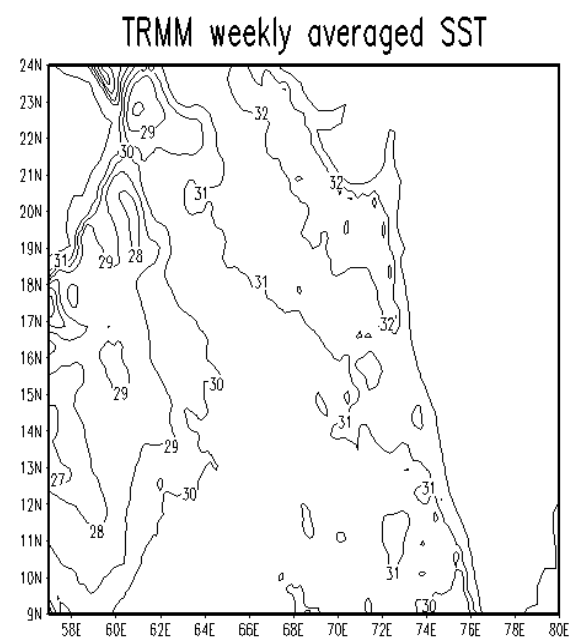

(b)

Fig. 2. Comparison of SST initial conditions: (a) Default/climatological SST $\left({ }^{\circ} \mathrm{C}\right)$ between May and August from 1950 to 1980 ; (b) TRMM satellite observed weekly averaged SST $\left({ }^{\circ} \mathrm{C}\right)$ 23-29 July 2005.

a) $850 \mathrm{hPa}$ Winds analysis

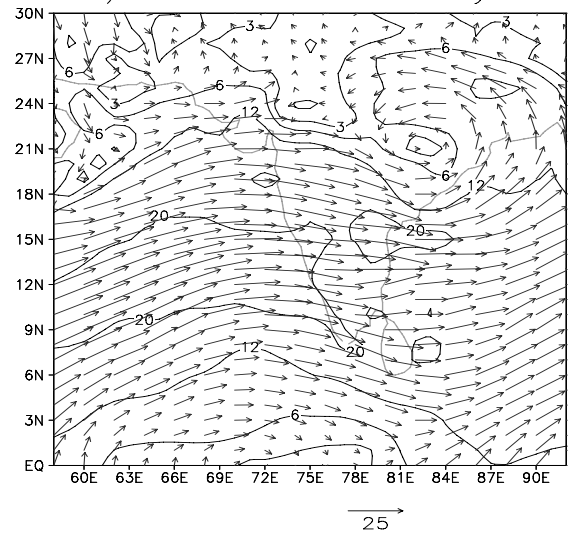

c) $850 \mathrm{hpa}$ winds simulation

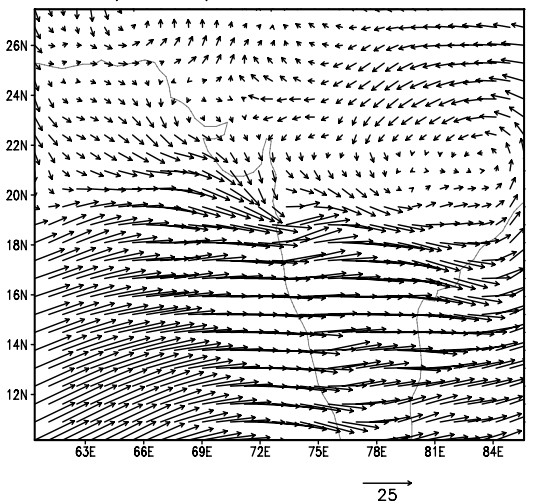

b) $300 \mathrm{hPa}$ Winds analysis

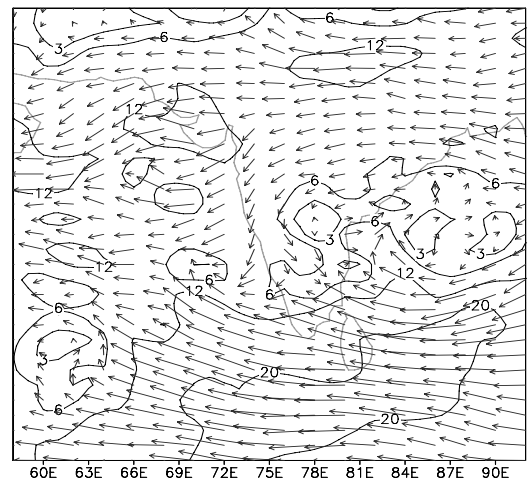

$\overrightarrow{25}$

d) 300 hpa Winds simulation

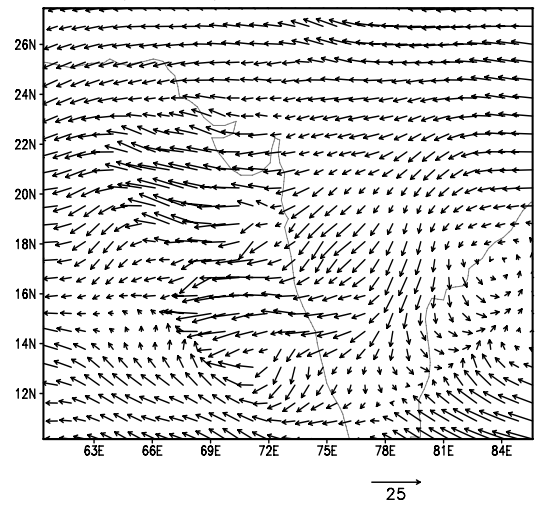

Fig. 3. Comparison of NCEP reanalysis and model-simulated wind circulation. $\left(\mathrm{m} \mathrm{s}^{-1}\right)$. 
Table 2b. Key variables (three layers) of roof, road and wall.

\begin{tabular}{llll}
\hline Key variables & Roof & Road & Wall \\
\hline Heat capacity $\left(\mathrm{MJ} \mathrm{m}^{-3} \mathrm{~K}\right)$ & $2.11,0.28,0.29$ & $1.94,1.28,1.28$ & $1.55,1.55,0.29$ \\
Thermal conductivity $\left(\mathrm{W} \mathrm{m}^{-1} \mathrm{~K}^{-1}\right)$ & $1.51,0.08,0.05$ & $0.7454,0.2513,0.2513$ & $0.9338,0.9338,0.05$ \\
Thickness (m) & $0.05,0.4,0.05$ & $0.05,0.1,1.0$ & $0.02,0.125,0.02$ \\
Albedo & 0.18 & 0.25 & 0.13 \\
\hline
\end{tabular}
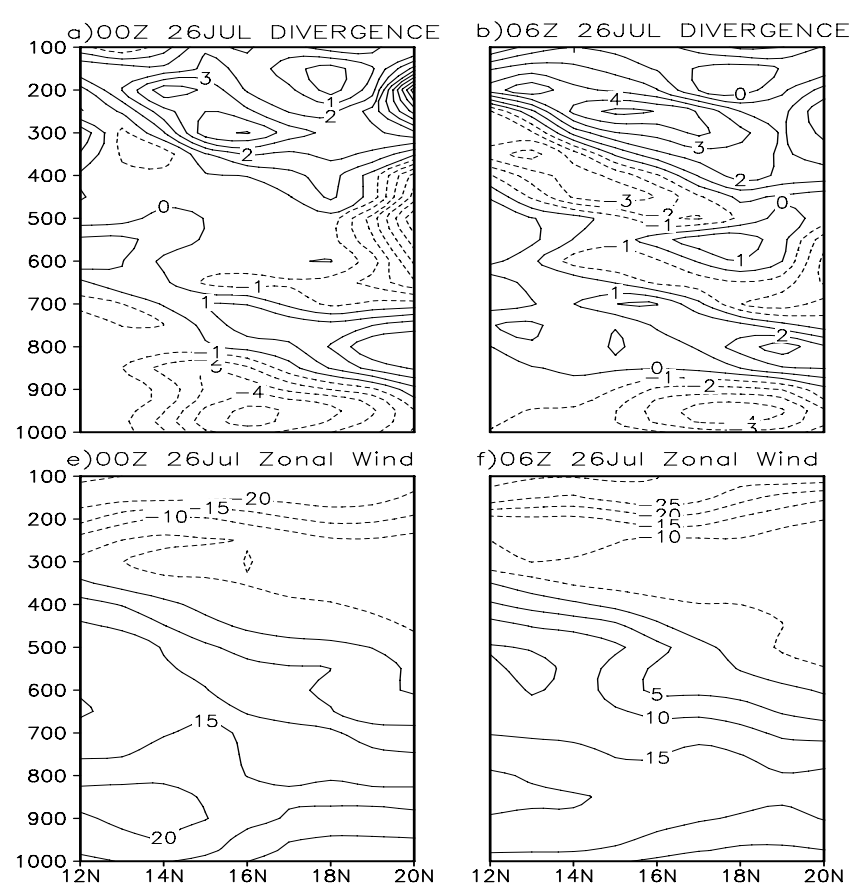
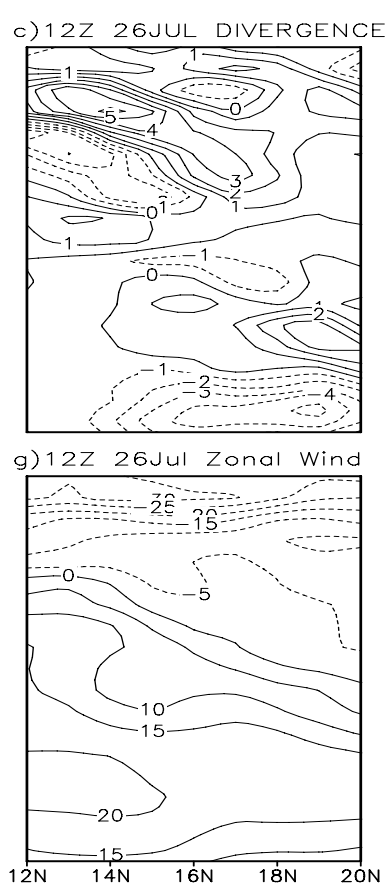

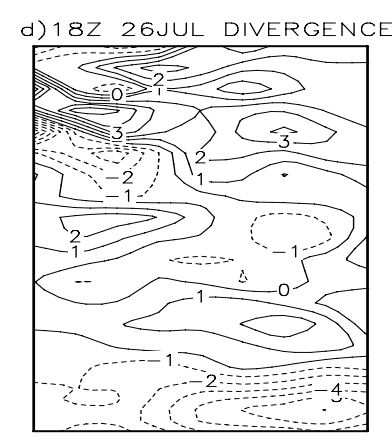

h) $18 \mathrm{Z} 26 \mathrm{Jul}$ Zongl Wind

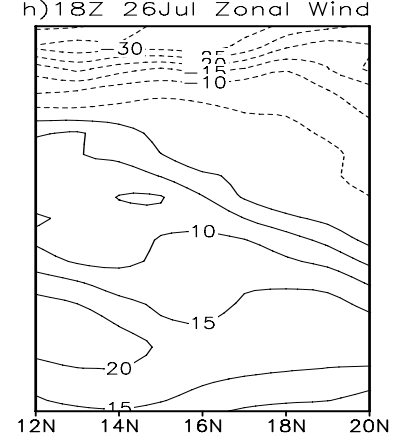

Fig. 4. NCEP reanalysis data for zonal divergence field $\left(10^{-4} \mathrm{~s}^{-1}\right)$ and zonal wind $\left(\mathrm{m} \mathrm{s}^{-1}\right)$ between $72.5 \mathrm{E}$ and $73.5 \mathrm{E}$. Y-axis is pressure in $\mathrm{mb}$.

been present in the Mumbai area for some time, along with a substantial increase in convergence below $700 \mathrm{hPa}$. This presence of a convergence pattern appears to be consistent with the observed changes in the rainfall intensity.

The vertical cross section of zonally-averaged wind (72.5 E-73.5 E) for this analysis at different times is shown in Fig. 4e-h. The zonal wind cross sections clearly illustrate the development of a low-level jet, which reaches a maximum of approximately $20 \mathrm{~m} \mathrm{~s}^{-1}$ near $700 \mathrm{hPa}$ at $12 \mathrm{Z}$ and $18 \mathrm{Z}$ on 26 July, respectively. The convective system that produced the intense rainfall appears to have developed over Mumbai just to the north of the low-level jet. The control experiments predicted the strong westerly or northwesterly winds over the western coast of India with a maximum speed of $20 \mathrm{~m} \mathrm{~s}^{-1}$. The model showed the presence of a strong cyclonic circulation over Orissa and the eastern part of Madhya Pradesh. The control experiment simulated the upper-level easterly or northeasterly flow reasonably well, with speeds of approximately $12 \mathrm{~m} \mathrm{~s}^{-1}$ over Mumbai. As a whole, both the upper- and lower-level large-scale circulation features are simulated reasonably well when compared with the corresponding NCEP analyses. The upper-level divergence and low- and mid-level convergence was simulated well in the mesoscale model run. All major features described in the analysis were satisfactorily reproduced, though some features, such as the low-level jet, were relatively weaker than the observations.

\subsection{Rainfall}

According to the official IMD rainfall observation over Santacruz (Table 3), the majority of the $950 \mathrm{~mm}$ total occurred from 14:30 to 20:30 26 July, 2006. The model simulated nearly $600 \mathrm{~mm}$ precipitation (approx.) in different experiments for the same period (Fig. 5). Simulations coupled with the TEB run showed consistently higher precipitation from 
Table 3. Temporal rainfall variation at Santacruz 26-27 July 2005.

\begin{tabular}{llll}
\hline Date & Hour IST & Rainfall $(\mathrm{mm})$ & Accumulated Rainfall $(\mathrm{mm})$ \\
\hline 26 July & $0830-1130$ & 0.9 & 0.9 \\
& $1130-1430$ & 18.4 & 19.3 \\
& $1430-1730$ & 380.8 & 400.1 \\
& $1730-2030$ & 267.6 & 667.7 \\
& $2030-2330$ & 101.1 & 768.8 \\
27 July & $2330-0230(27$ th) & 116.2 & 885 \\
& $0230-0530$ & 11.0 & 896 \\
Total & $0530-0830$ & 48.2 & 944.2 \\
\hline
\end{tabular}

noon of 26 July, indicating the significance of incorporating explicit urban model surface effects of urbanization. This feedback is discussed in more detail in the following section.

Both the Tropical Rainfall Measuring Mission (TRMM) satellite and the CPC MORPHing technique (CMORPH) from the NCEP analysis over the Indian subcontinent on 26 July 2005 showed a localized hotspot over Mumbai (Fig. 6a, b). Figure $6 \mathrm{c}$ depicts the spatial precipitation distribution regressed from gauge data. The RAMS-simulated precipitation with, without TEB and their difference is shown in Fig. 6d-e. Both precipitation measures are highly concentrated over the Mumbai region. The model run that includes the TEB had some significant spatial differences which are discussed below.

\subsection{Vertical structure/sounding}

One of the important sources of observation data, sounding profiles, are useful in understanding the atmosphere's vertical structure. The prestorm sounding data (0Z 26 July), and sounding data during the storm (12Z 26 July), were available for analysis over Mumbai (Fig. 7).

At 00Z 26 July 2005 (Fig. 7a) from ground surface to $3000 \mathrm{~m}$, the air temperature decreased with height, and air temperature in the TEB run generally matched observations, although the control results were within $1 \mathrm{~K}$. Similar results were obtained for virtual potential temperature from the ground surface to $500 \mathrm{~m}$. The TEB results were generally closer to observations, being about $1 \mathrm{~K}$ higher than the observations, and the control run result was slightly lower. From $1000-3000 \mathrm{~m}$, the TEB results more closely matched the observations, with the control results being about $1 \mathrm{~K}$ higher than the observations. Relative humidity from the observations showed a decrease from 600 to $3000 \mathrm{~m}$ height. The TEB results captured this trend, but the control run showed a saturated condition at about $600 \mathrm{~m}$. For wind speed, sounding data showed stronger values at about $1000 \mathrm{~m}$. This structure was simulated well by the TEB run, but at $900 \mathrm{~m}$ height the maximum winds were underestimated. In the control run, the wind profile did not show a jet and reached a maximum

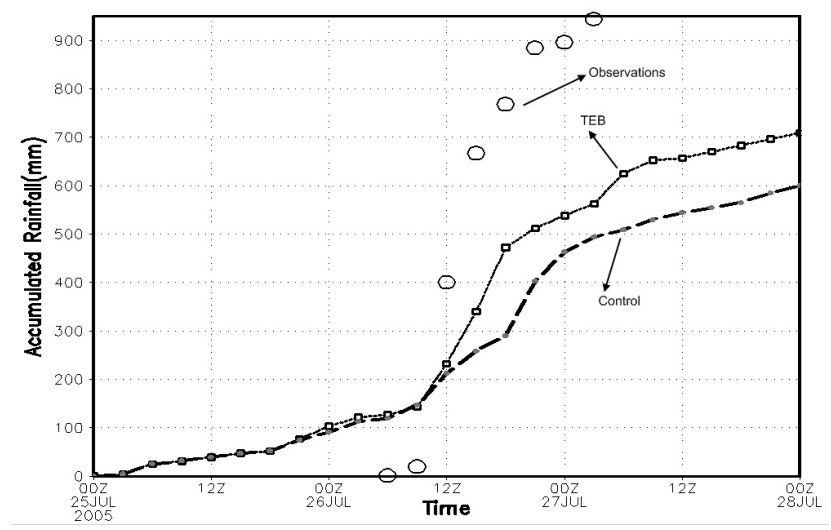

Fig. 5. Time series for precipitation over Santacruz Airport $\left(19^{\circ} 5^{\prime} \mathrm{N}, 72^{\circ} 50^{\prime} \mathrm{E}\right)$ : Circles show the observed raingauge rainfall $(\mathrm{mm})$, solid line with open squares=TEB Run $(\mathrm{mm})$, dashed line with dots=control run $(\mathrm{mm})$.

speed at a height of about $2000 \mathrm{~m}$. Thus overall, the TEB run appears to be superior than the control in simulating a vertical structure that is closer to the observations.

The $12 Z 26$ July sounding corresponds to the time Mumbai was experiencing heavy rainfall (Fig. 7b). Generally the sounding data had a high uncertainty during the heavy precipitation, but these data still can serve as a reference for analysis. Air temperature and virtual potential temperature $(\theta v)$ were nearly identical in the TEB and control runs. Both results were reasonable, and the structures for air temperature and $\theta v$ match well with the observations. Simulated relative humidity was saturated, which is reasonable considering the heavy rain, even though the sounding data does not show saturation. Wind speed during the heavy precipitation event was high at $1500 \mathrm{~m}$ height according to the observations. Neither TEB nor control captured this well. Above $2300 \mathrm{~m}$, the TEB result was closer to the observations. 


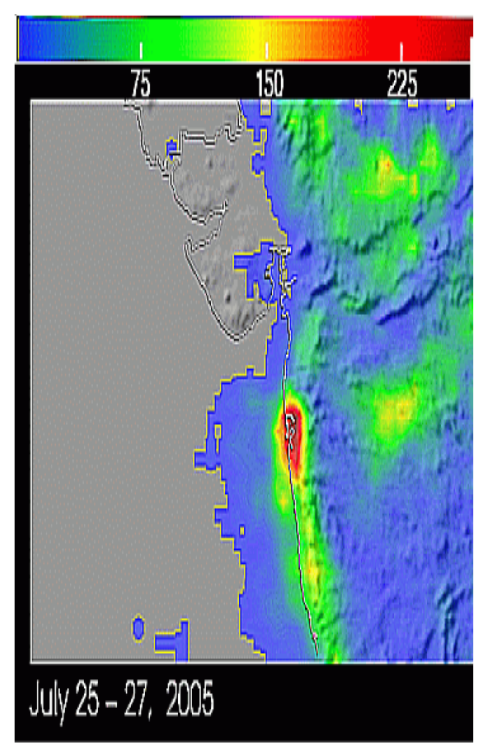

(a) TMI precipitation ( $\mathrm{mm})$

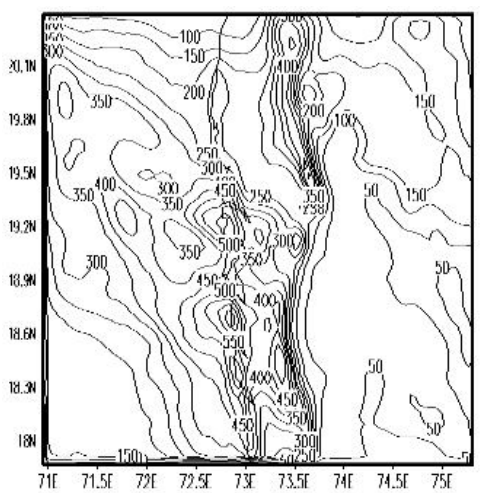

(d) Control (mm)
CMORPH precipitation $(\mathrm{mm}) 25$ th to 27 th

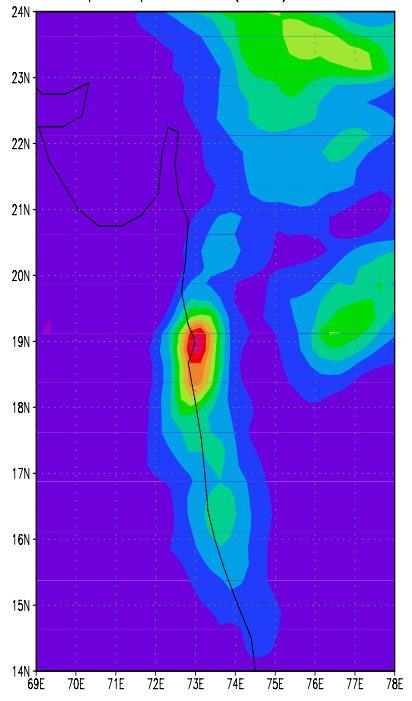

(b) CMORPH (mm)

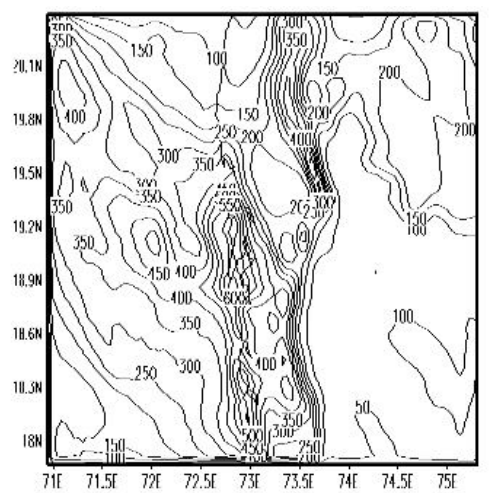

(e) TEB (mm)

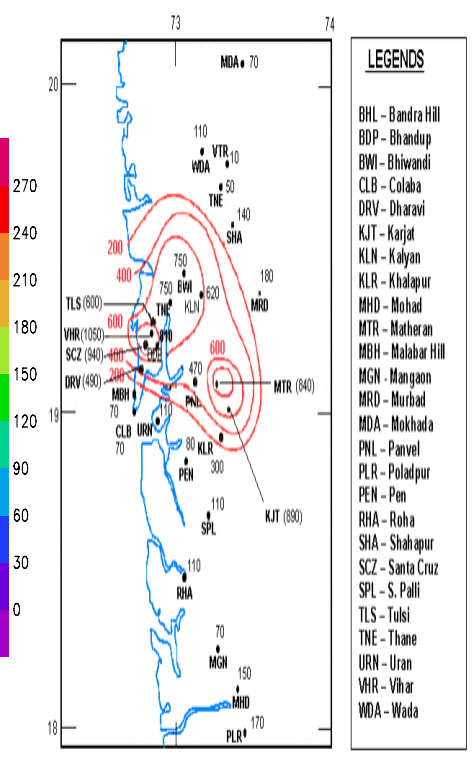

(c) Gauge data $(\mathrm{cm})$

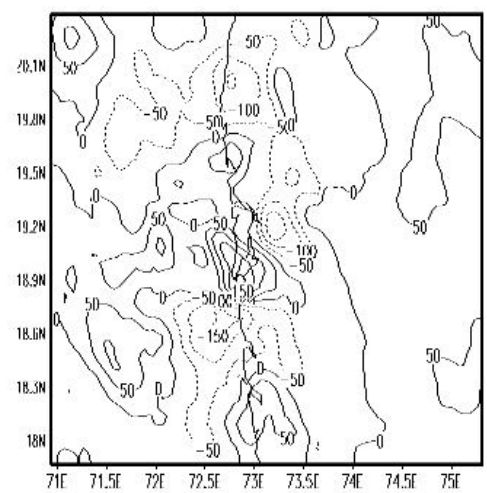

(f) TEB - Control (mm)

Fig. 6. Spatial precipitation (mm) captured by TRMM Microwave Imager (TMI), CMORPH: CPC MORPHING technique, gauge data, and simulation results.

\section{Impact of coupling TEB within RAMS}

The simulation results discussed above indicate that the mesoscale model (RAMS), when coupled with the explicit urban model TEB, has an enhanced ability to reproduce the boundary layer over urban areas. In this section we further discuss the impact of representing an explicit urban model within the mesoscale modeling system.
4.1 Temperature and flux change over the urban region (UHI simulation)

The urban heat island (UHI) appears to be well simulated by RAMS TEB around the Mumbai region (however temperature observations are not available). Figure 8 shows the $10 \mathrm{~m}$ air temperature change which occurred when using the explicit urban representation. The urban region had a significant UHI both in the daytime and the night. During the monsoon season, generally the cloud cover over the west coast of India is high. This feature was well simulated by the model and the simulated cloud cover over the coastal land region to 

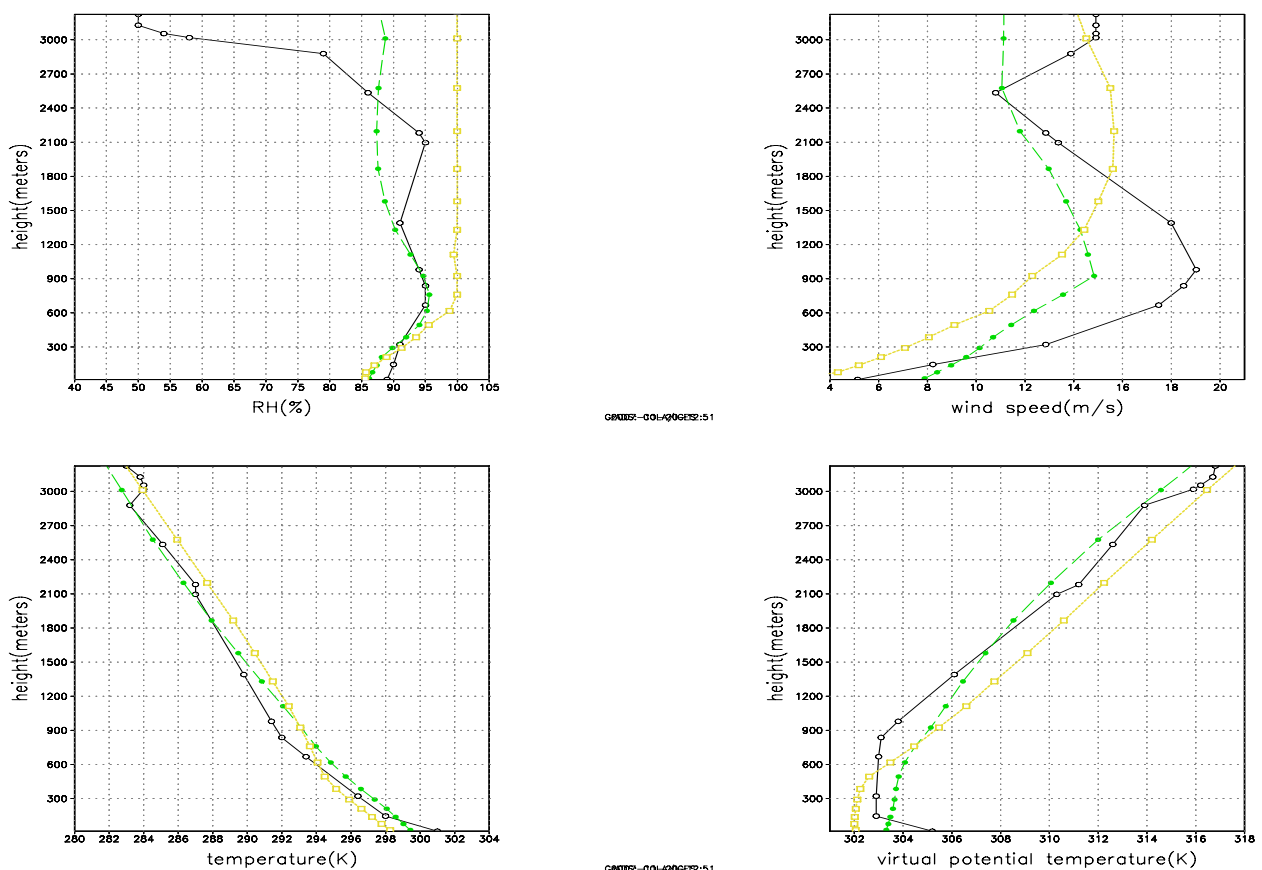

(a) Vertical sounding at 00Z 26 July GMT
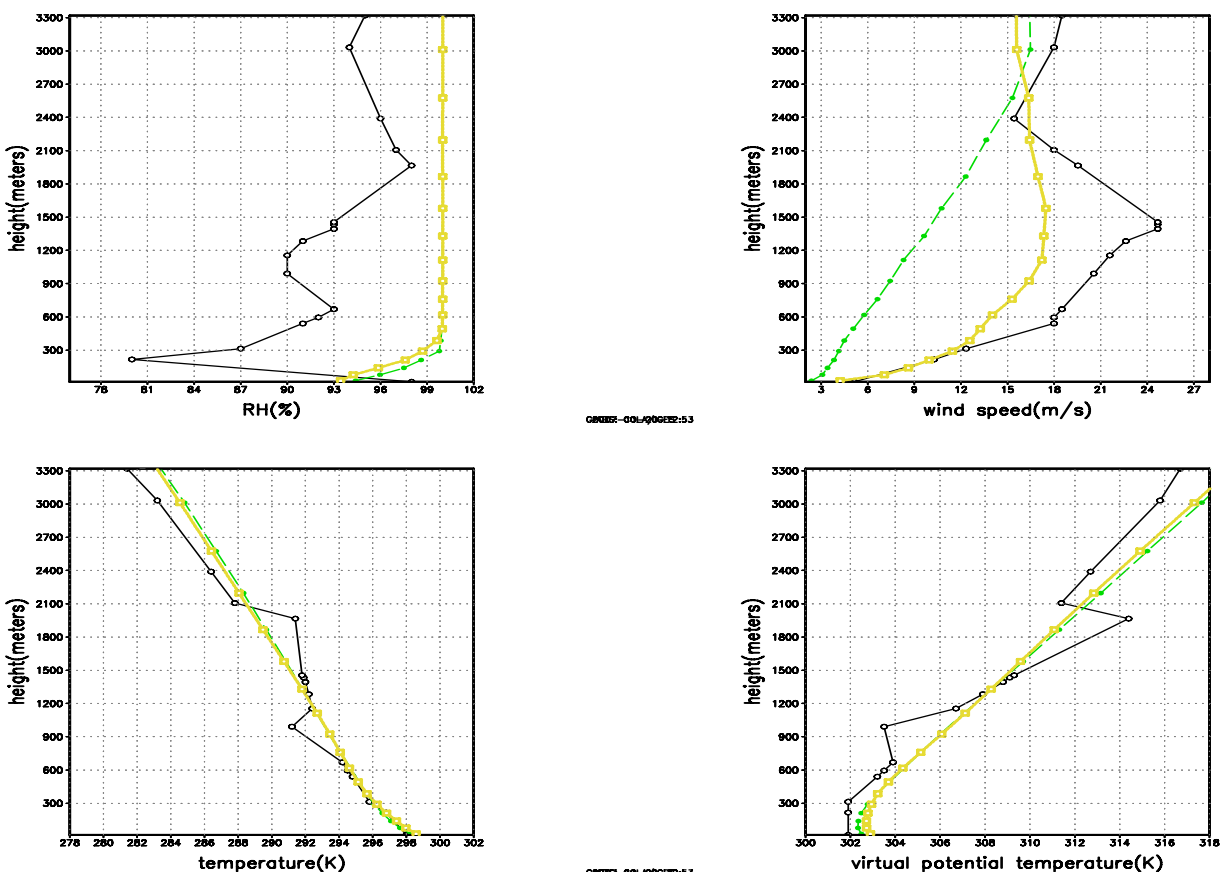

(b) Vertical sounding at 12Z 26 July GMT

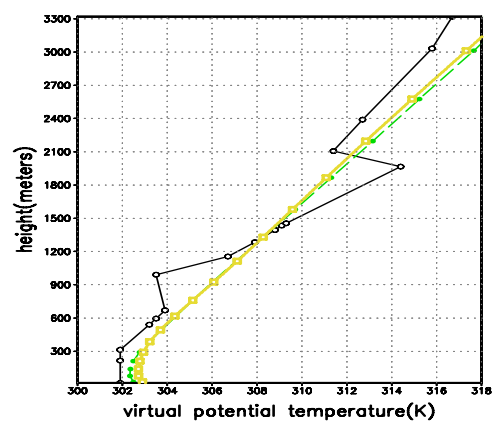

Fig. 7. Comparison of observed sounding data and simulations from RAMS at the Santacruz airport weather station. Solid line with open circles=observation; dashed line with dots=TEB; light grey dashed line with open squares=control. 

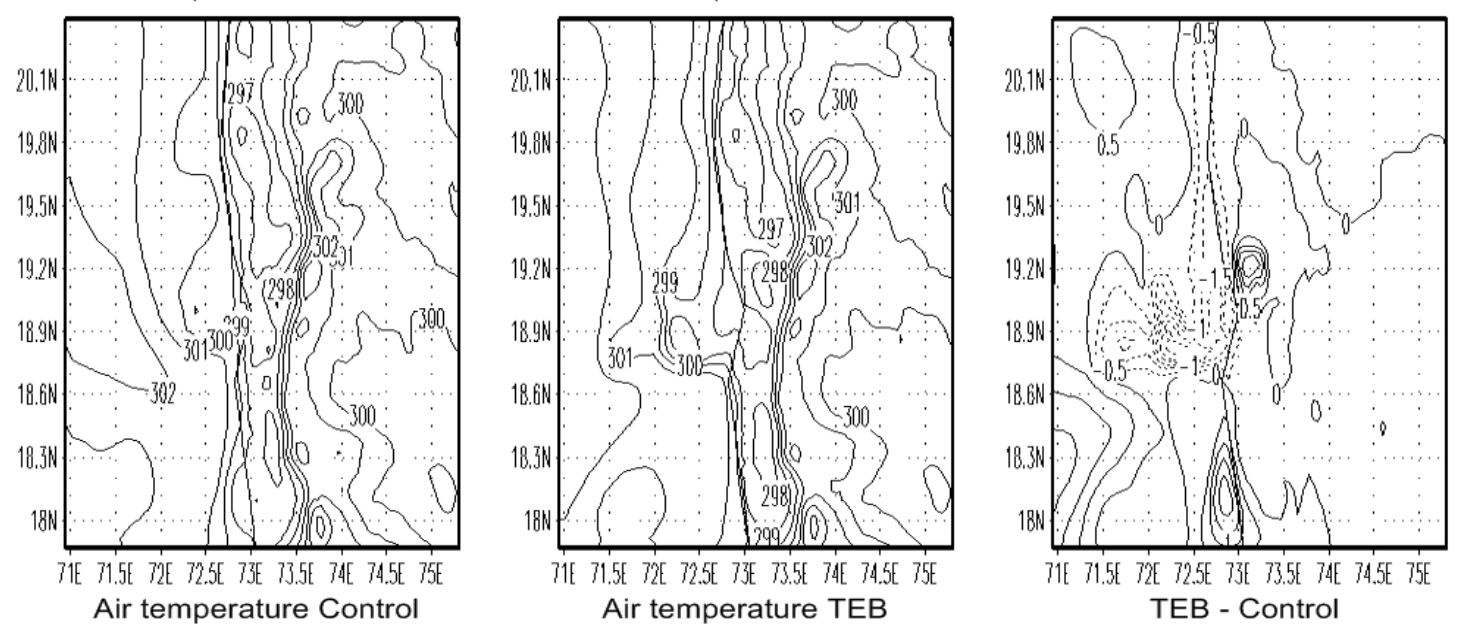

(a) $1000 \mathrm{hpa}$ air temperature (K) at 00Z 26 July
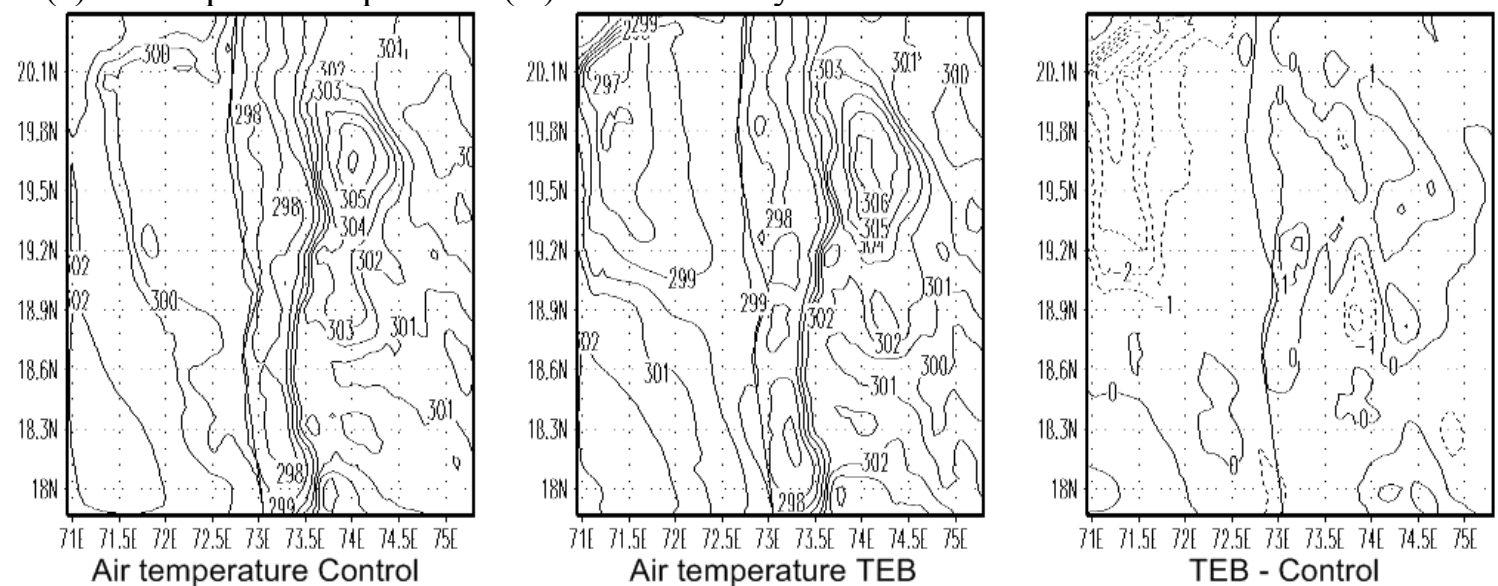

(b) 1000 hpa air temperature (K) at 06Z 26 July
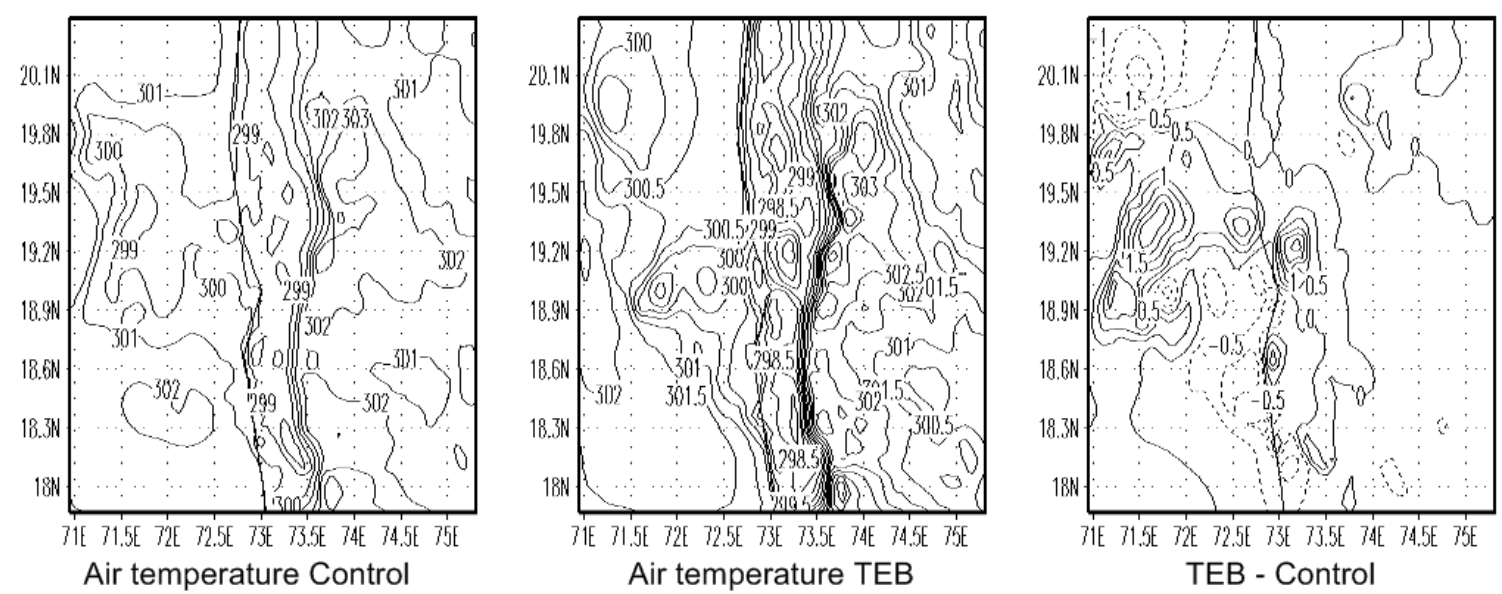

(c) 1000 hpa air temperature (K) at $12 \mathrm{Z} 26$ July

Fig. 8. $1000 \mathrm{mb}$ air temperature (K) changes due to urbanization (using TEB). 

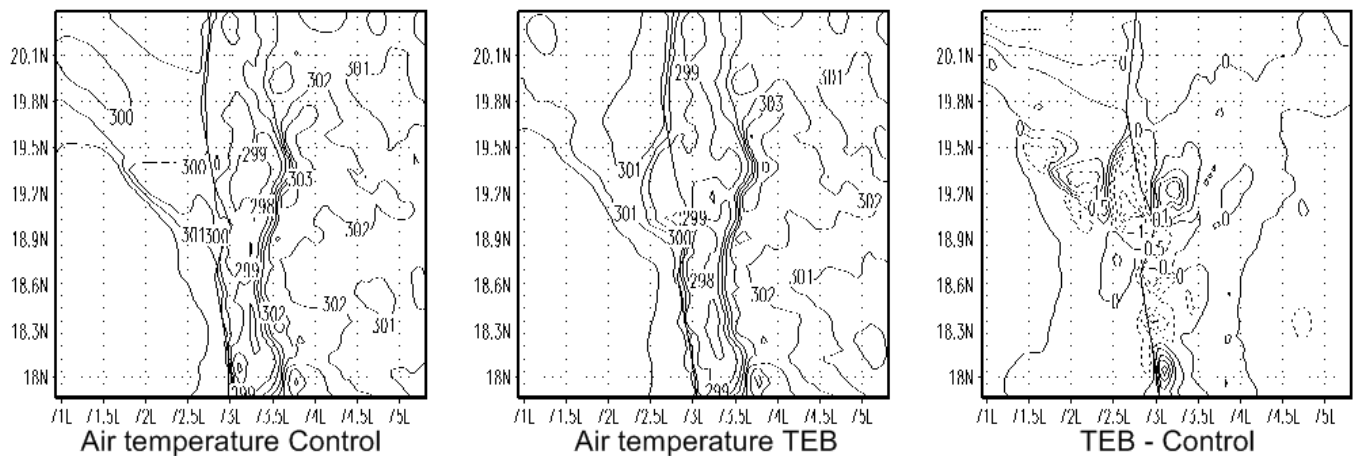

(d) 1000 hpa air temperature (K) at $18 \mathrm{Z} 26$ July
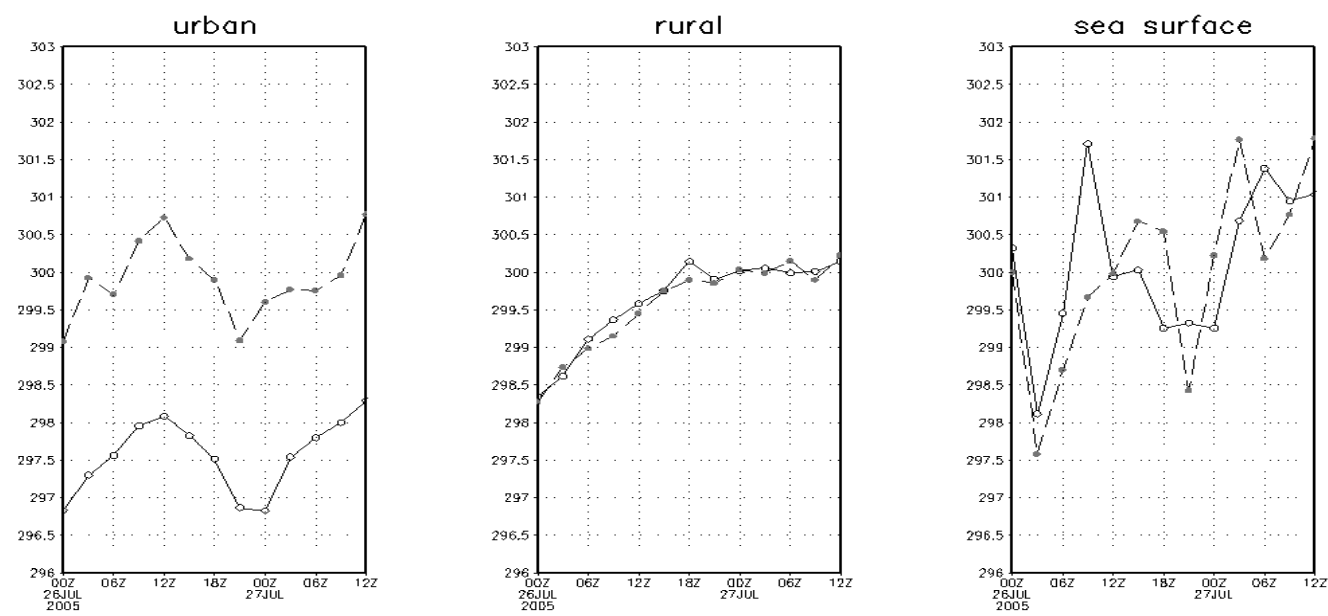

(e) 1000 hpa air temperature $(\mathrm{K})$ time series over urban location: $(19.15 \mathrm{~N}, 72.9 \mathrm{E})$; rural location: (19.15 N, $73.2 \mathrm{E})$; sea surface location: (19.15 N, $72 \mathrm{E})$. Solid line with open squares: control run; dashed line with closed squares: TEB run.

Fig. 8. Continued.

the west of India is close to $100 \%$ (not shown). This caused the incident solar radiation near the surface to be quite low. The low-level wind during the period was controlled by the south Asian monsoon and the strong southwest wind feature, therefore, air temperatures increased above the urban region and above downwind and northeast of Mumbai city, a similar feature is reported over Atlanta by Bornstein and Lin (2000). Figure $8 \mathrm{a}-\mathrm{d}$ show air temperature changes at $0 \mathrm{Z}, 6 \mathrm{Z}, 12 \mathrm{Z}$, and $18 \mathrm{Z}$ for the two runs. The corresponding diurnal time series over an urban, rural, and offshore locale is displayed in Fig. 8e. Throughout the day, the warming zone extended from the city center to the northeast direction of the city with a $1-2 \mathrm{~K}$ higher temperatures than in the surroundings. The size of this region, which experienced a significant warming due to UHI, is about $50 \times 50 \mathrm{~km}$ with an extended area in the northeast downwind direction. Comparing different times within one day, the UHI was apparent for most of the day except the afternoon when heavy precipitation occurred and cloud cover was at its highest. In the upwind direction from urban region, there was a cooling from $0.5-1 \mathrm{~K}$ just over the Mumbai coastal region. This cooling was probably because of the rainfall over the region and the general associated circulation.

The simulation clearly showed that the UHI was generally more significant downwind of the city from $73 \mathrm{E}-73.5 \mathrm{E}$. Vertically, the higher air temperature was typically noted up to a height of $400 \mathrm{~m}$ above the surface (Fig. 9). The warming effect decreases with height: at $100 \mathrm{~m}$ TEB results were $1 \mathrm{~K}$ warmer; this difference decreased to nearly $0.5 \mathrm{~K}$ at $200 \mathrm{~m}$, and then the warming effect essentially disappeared. The UHI effect was distributed downwind direction of Mumbai city, especially in the $73^{\circ} \mathrm{E}$ to $73.5^{\circ} \mathrm{E}$ region.

One key mechanism of low-level jet formation involves horizontal differences in heat fluxes, which can produce strong, shallow baroclinicity in the boundary layer (Stensrud, 1996). The low-level jet in many other heavy precipitation events has been found to be enhanced because of the gradient in sensible and latent heat fluxes, this spatially varying 


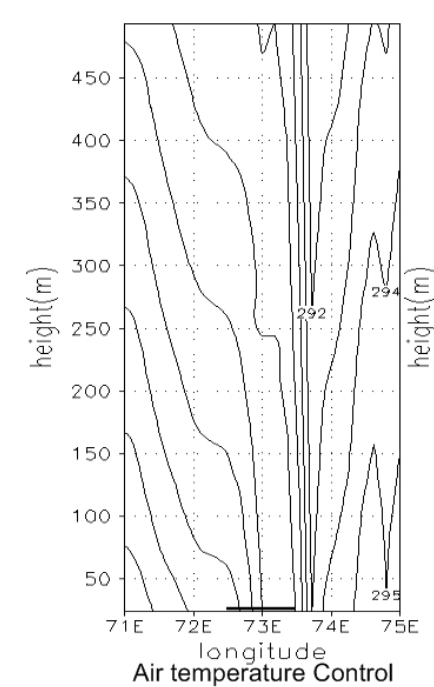

Air temperature Control

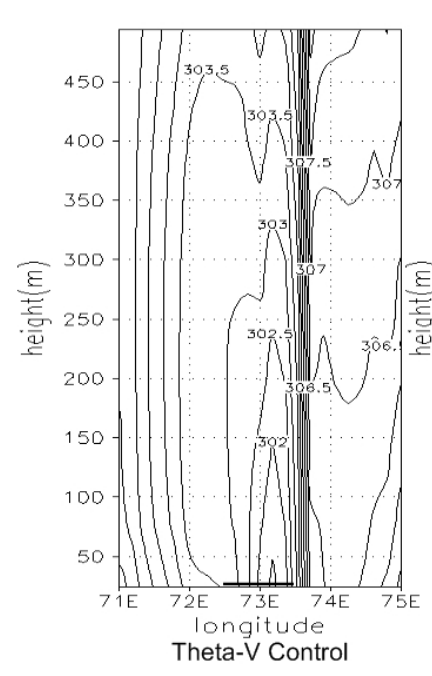

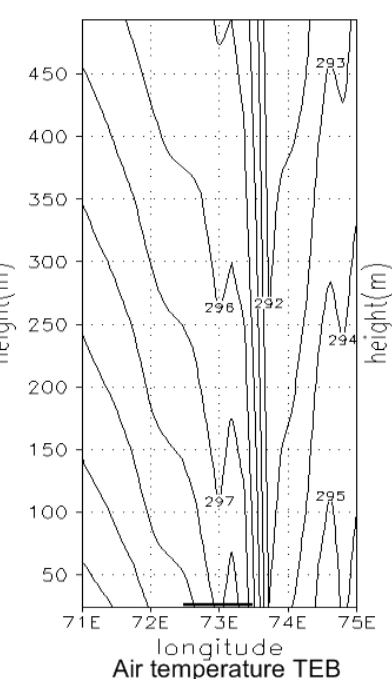

(a)

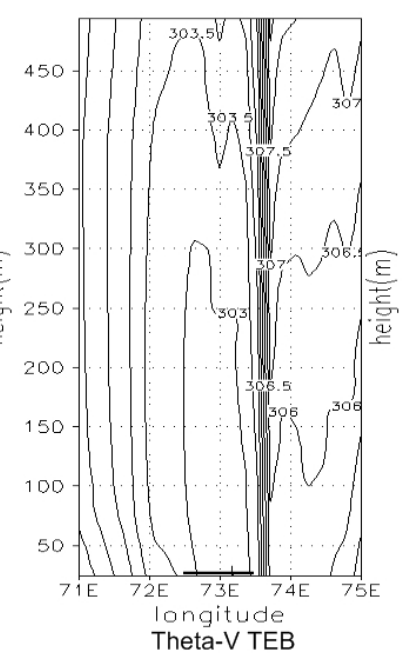

(b)

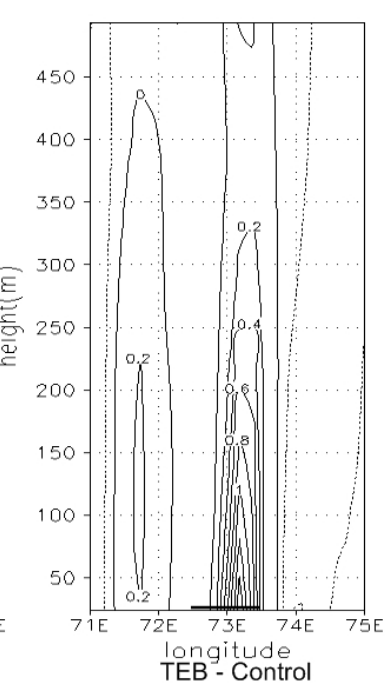

TEB - Control

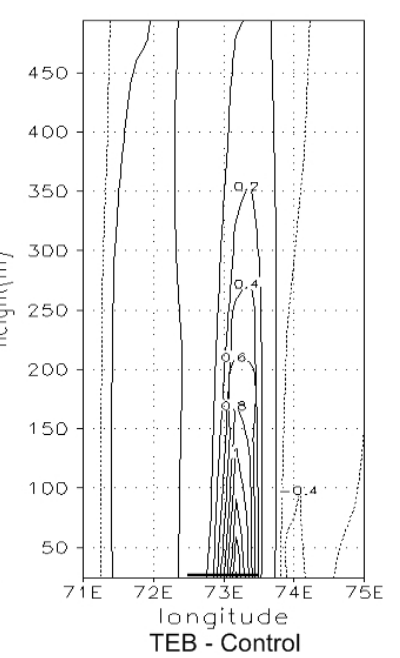

Fig. 9. Cross-section of (a) vertical air temperature (K) and (b) Theta-V (K, virtual potential temperature) profiles over the Mumbai urban region.

flux distribution has been attributed to gradients in soil moisture (Holt et al., 2006). Consistent with the surface air temperature results discussed above, and as observed over Mumbai city, the sensible heat flux increased after urbanization (using the TEB) by approximately $50 \mathrm{~W} \mathrm{~m}^{-2}$ (Fig. 10). During a $24 \mathrm{~h}$ time period, the UHI was more significant during the night (00:00 a.m.) and early morning (06:00 a.m.), consistent with previous conclusions that the UHI was relatively more significant after late afternoon (Fig. 9) (Oke, 1987; Niyogi et al., 2006).

The interaction of the land-surface and the atmosphere can also produce high spatial variability in latent heat fluxes. This land-surface interaction is another important process for producing variability in tropical rainfall. Figure 11 shows the temporal latent heat fluxes. As expected, the TEB did not change the latent heat flux significantly due primarily to the very low evaporation over the urban region. The latent heat flux showed a slight decrease by about $50 \mathrm{~W} \mathrm{~m}^{-2}$ in the upwind direction over the sea most likely due to the precipitation increase and temperature decrease over this area.

\subsection{Winds and convergence}

From the simulation results, over the city on the afternoon of 26 July an obvious vertical updraft was apparent both in the control and the TEB simulations (Fig. 12). With the urban TEB run, the updrafts are generally in the upwind direction (Fig. 12). The enhancement in the vertical velocity 

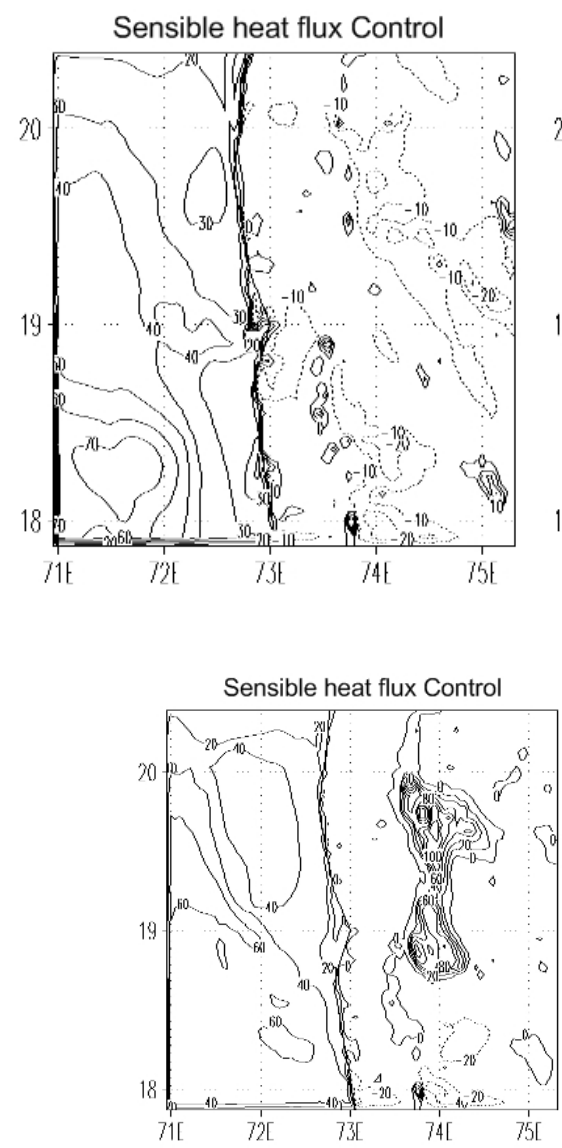
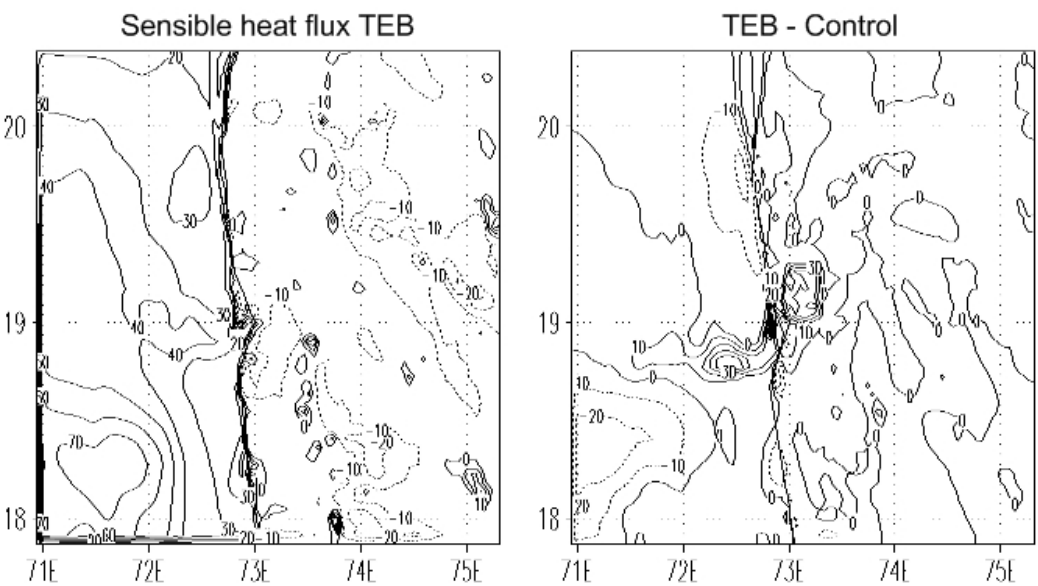

(a) 00Z 26 July 2005
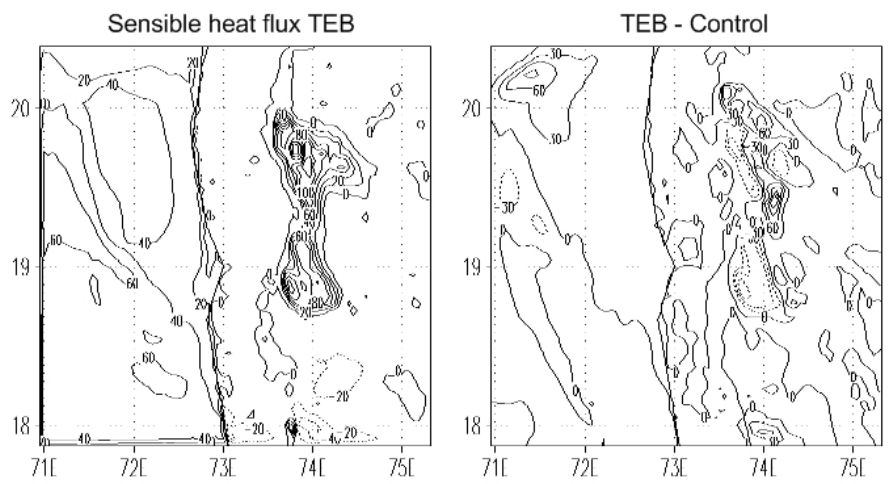

(b) 06Z 26 July 2005

Fig. 10. 26 July sensible heat fluxes $\left(\mathrm{W} \mathrm{m}^{-2}\right)$ in both simulations and changes after coupling with urban model.

is $0.5 \mathrm{~m} \mathrm{~s}^{-1}$. Convergence changes associated with wind, roughness change, and thermal conditions are shown in Fig. 13a-b. For $12 Z$ on 26 July, with the TEB run, the lowlevel offshore winds are slower. The control run shows a lower wind speed zone over the city with a speed of $10 \mathrm{~m} \mathrm{~s}^{-1}$ up to about $200 \mathrm{~m}$ high, and the TEB run shows the low wind zone at $10 \mathrm{~m} \mathrm{~s}^{-1}$ over $1000 \mathrm{~m}$. The wind speed above the urban region below a height of $500 \mathrm{~m}$ decreases from $10 \mathrm{~m} \mathrm{~s}^{-1}$ to $2 \mathrm{~m} \mathrm{~s}^{-1}$ (Fig. 13b). This change due to urbanization indicates increased convergence in the upwind direction. As seen in Fig. 13b, from the ground surface to a height of $3000 \mathrm{~m}$ at $72^{\circ} \mathrm{E}$, a significant convergence zone developed over Mumbai. With the TEB run, the results indicated that the low-level convergence increased up to $3000 \mathrm{~m}$ and decreased thereafter. A modeling study by Thielen et al. (2000) also found that increased roughness led to higher precipitation near the urban area.

NCEP analysis also shows a similar trend with the divergence field for different times on 26 July (Fig. 4). The analysis indicates that upper-level divergence overlying deep, lowand mid-level convergence existed over the Mumbai region and a substantial increase in convergence below $700 \mathrm{mb}$ occurred that helped enhance the moisture transport.

\subsection{Rain water mixing, cloud water mixing ratio, and pre- cipitation}

Consistent with the vertical wind fields, the rain water mixing ratio in the TEB run also increased upwind of the city and decreased in the center and downwind of the city compared to the control run (Fig. 14). Above the urban region in the upwind direction, the rain water mixing ratio was modified due to urbanization. This ratio increased from $1 \mathrm{~g} \mathrm{~kg}^{-1}$ to about $1.4 \mathrm{~g} \mathrm{~kg}^{-1}$ up to $4500 \mathrm{~m}$ in height. The cloud water mixing ratio shows a similar trend (Fig. 15). Figure 15 shows the cloud water mixing ratio at $12 \mathrm{Z} 26$ July. The control run shows that the cloud water ratio has increased between the heights of $2000-6000 \mathrm{~m}$ with the maximum zone at $5000 \mathrm{~m}$ generally occurring above the $72^{\circ} \mathrm{E}$ to $73.5^{\circ} \mathrm{E}$ region. After urbanization, the upwind area from $71.5^{\circ} \mathrm{E}$ to $72.5^{\circ} \mathrm{E}$ around $19.15^{\circ} \mathrm{N}$ had a higher cloud water mixing ratio around $5000 \mathrm{~m}$. The cloud water mixing ratio was modulated by vertical winds (Fig. 15). As a result 

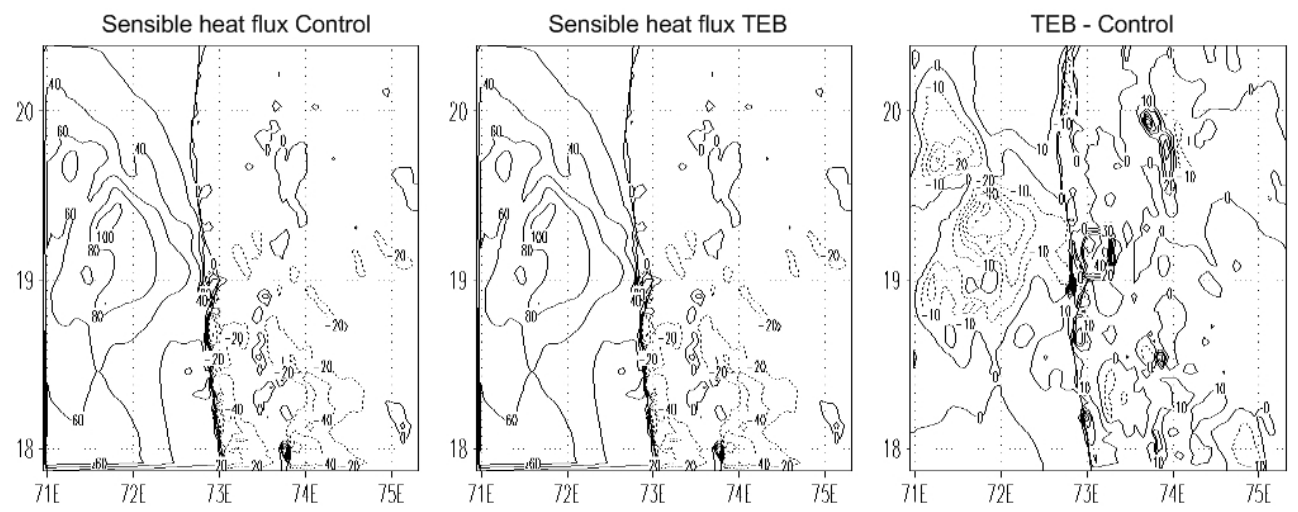

(c) 12 Z 26 July 2005
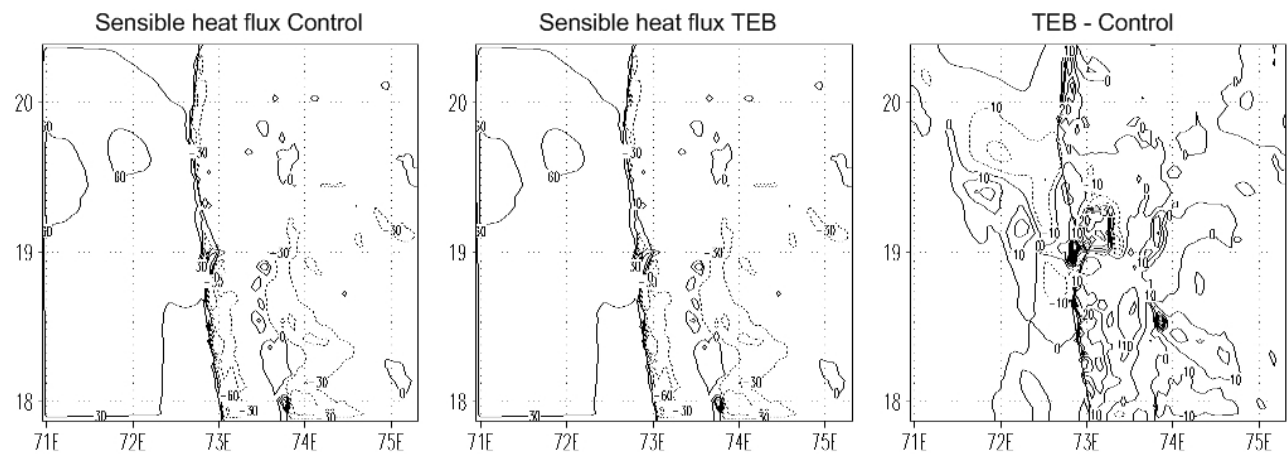

(d) $18 Z 26$ July 2005
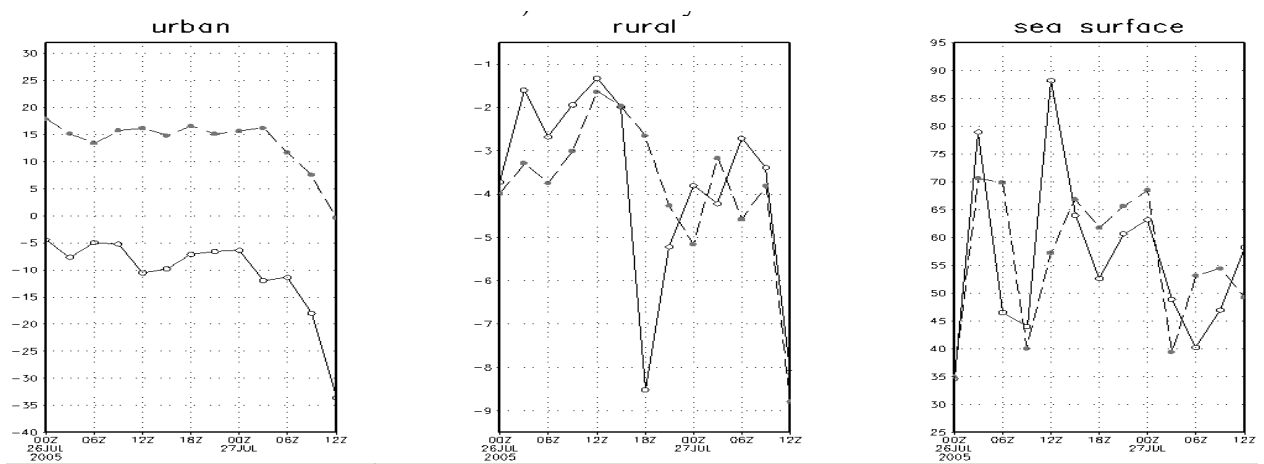

e) Sensible heat flux $\left(\mathrm{W} \mathrm{m}^{-2}\right)$ time series over urban location: $(19.15 \mathrm{~N}, 72.9 \mathrm{E})$; rural location: (19.15N, 73.2E); sea surface location: (19.15N, 72E). Solid line with open squares: control run; Dashed line with closed squares: TEB run.

Fig. 10. Continued.

of these changes after urbanization, precipitation distribution and intensity were both significantly influenced by mesoscale dynamical feedbacks. As displayed previously in Fig. 6, the accumulated precipitation from 25-27 July 2005 for the control run indicates that the precipitation location is not well represented; the precipitation was split into two rain centers over north and south Mumbai city. After coupling with the TEB, the model precipitation appears correctly over the Mumbai bay area and was increased by a significant amount (200 mm).

\section{Analysis of the explicit SST and the urban land- atmosphere interactions}

To further resolve the explicit role of the urban model and satellite-captured SST on the convection, we performed a statistical factor separation analysis (Stein and Alpert, 1993) from 26-27 July 2005. Model-simulated vertical velocity, convergence, and 12-h accumulated precipitation were analyzed. The intent of the analysis was to quantify the relative impacts of (i) the representative urban model (f2), (ii) the 

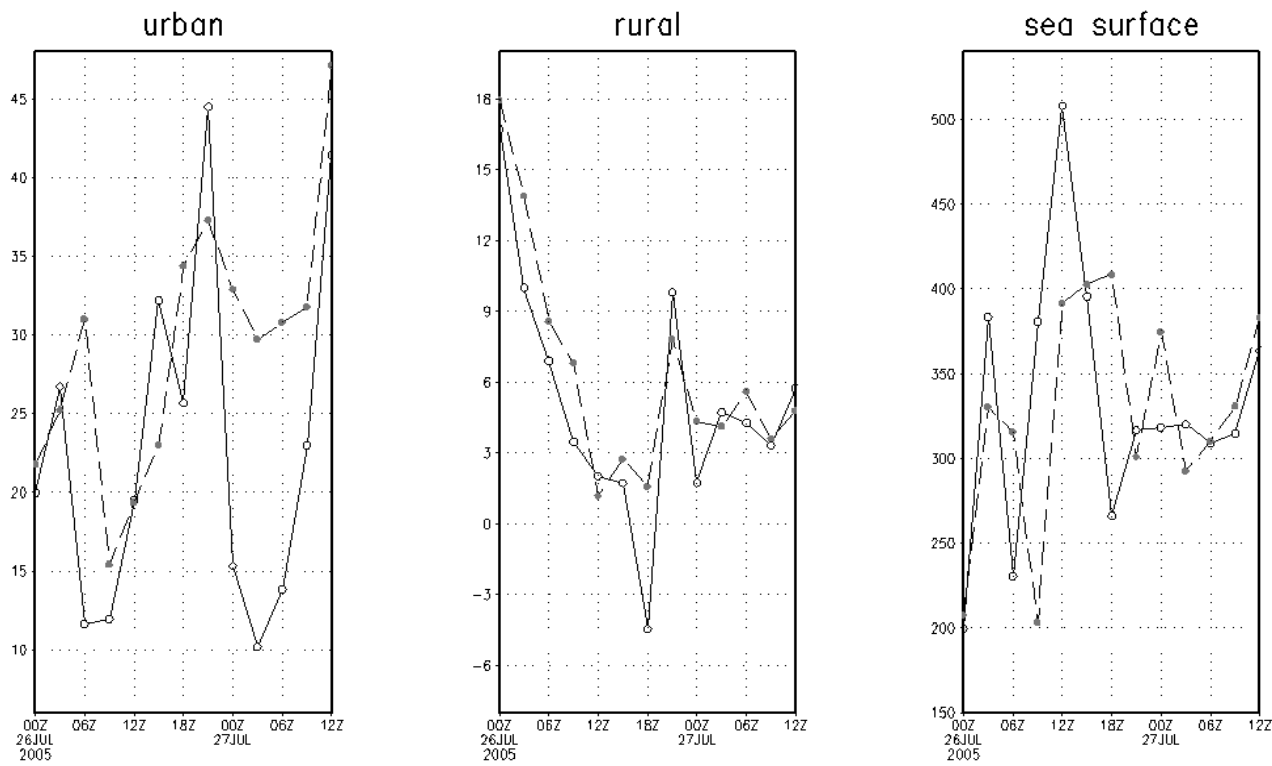

Fig. 11. Same as Fig. 10e but for latent heat flux. $\left(\mathrm{W} \mathrm{m}^{-2}\right)$.
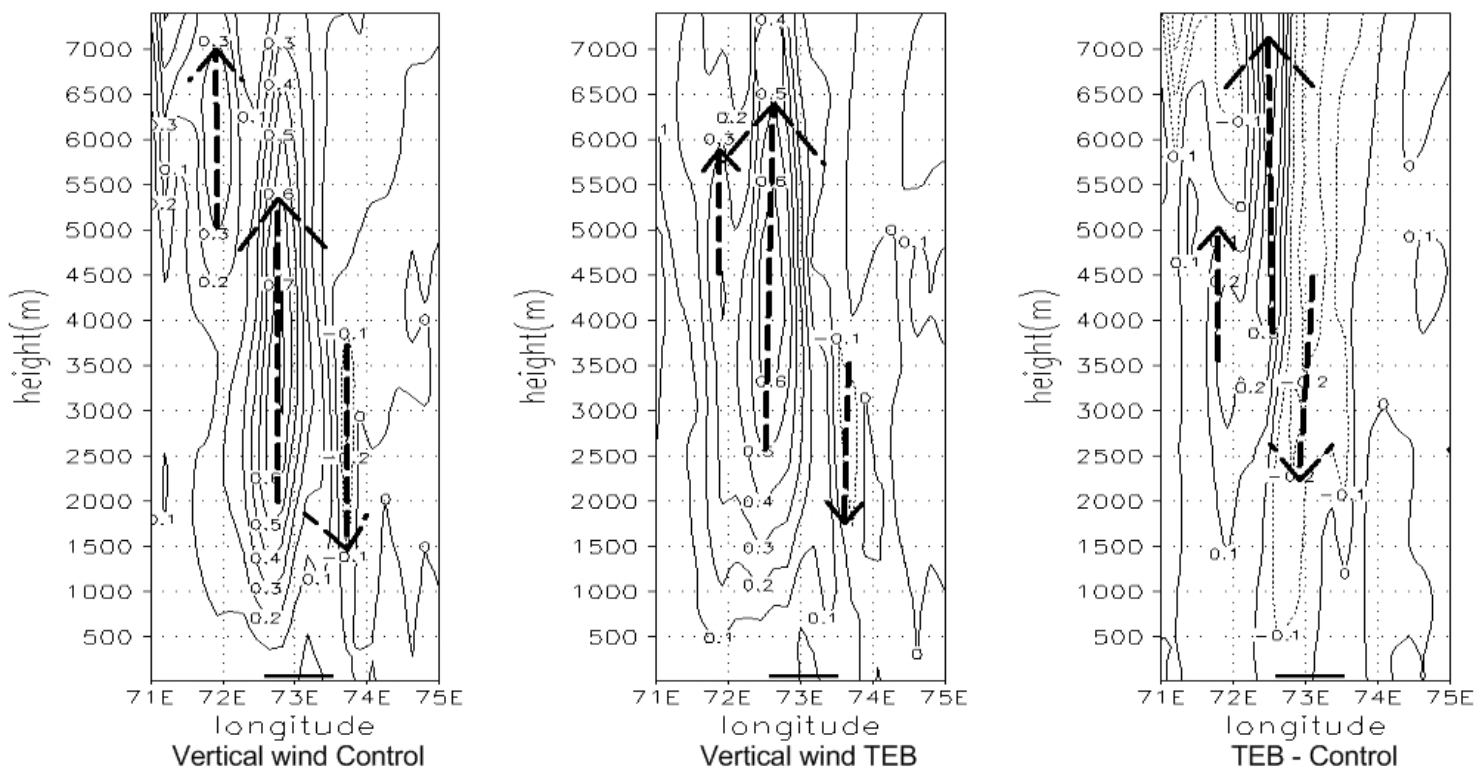

Fig. 12. Cross-section of vertical wind at $12 \mathrm{Z} 26$ July and its change $\left(\mathrm{m} \mathrm{s}^{-1}\right)$ after using the urban model.

improved satellite SST data (f1), and (iii) improvements in both the urban model and SST representations (f12). According to Stein and Alpert (1993), the relative impacts f1, $\mathrm{f} 2$ and $\mathrm{f} 12$ are given by the field differences between the simulations F0, F1, F2 and F12 as:

$\mathrm{f} 1=\mathrm{F} 1-\mathrm{F} 0$

$\mathrm{f} 2=\mathrm{F} 2-\mathrm{F} 0$

$\mathrm{f} 12=\mathrm{F} 12-(\mathrm{F} 1+\mathrm{F} 2)+\mathrm{F} 0$ where F0 is the climatological SST without the TRMM SST fields or the urban model, F1 is the simulation with TRMM SST but without the urban model, F2 is the simulation with the urban model TEB but without TRMM SST, and F12 is the simulation using both TRMM SST and the urban model TEB. The analysis in the previous section showed that the convergence pattern over Mumbai is an important variable which links the atmospheric condition to the precipitation. Because the maximum intensity occurred between 10 and $11 \mathrm{Z}$, we focus on the spatial convergence at $850 \mathrm{hPa}$ level 

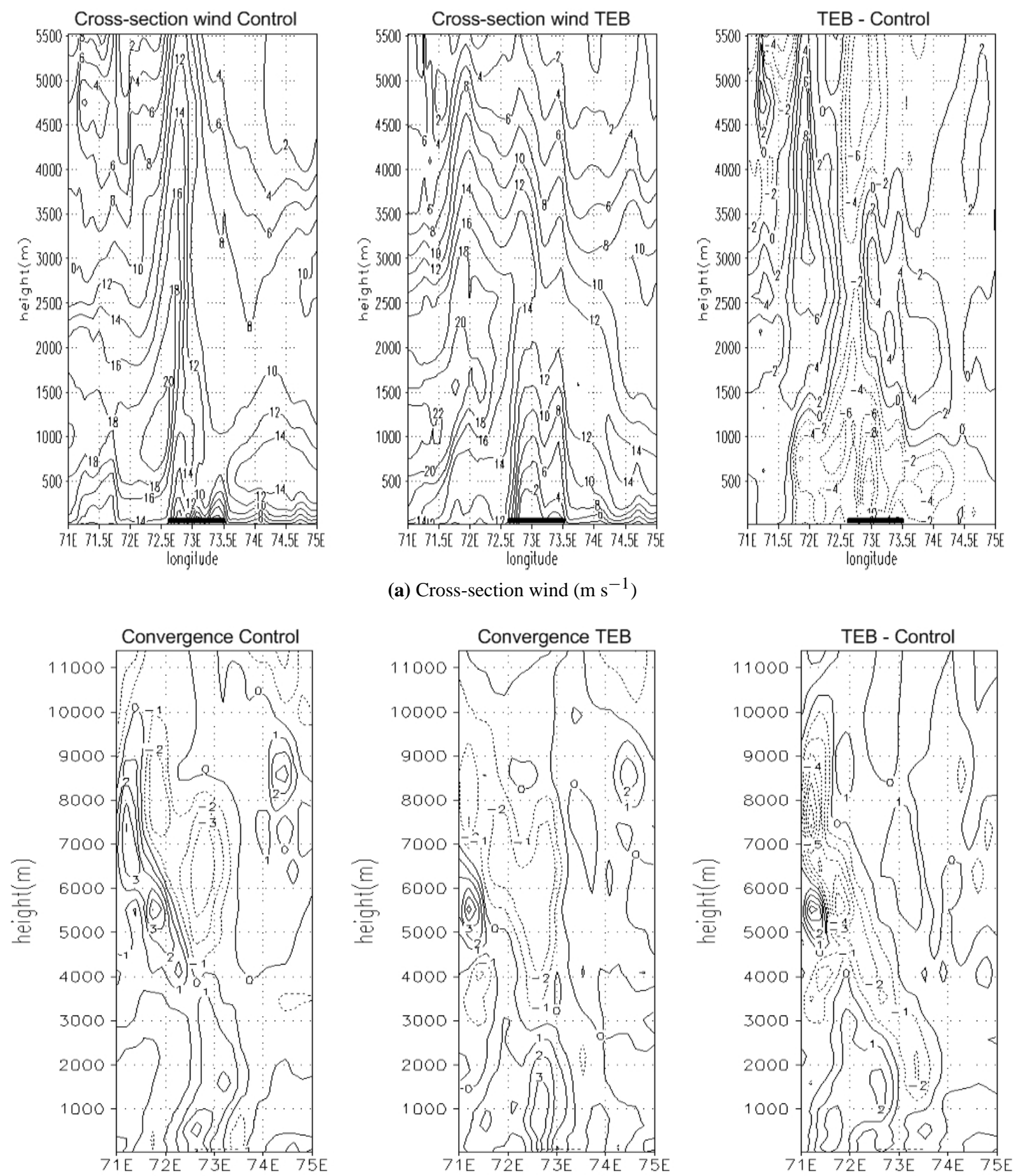

(b) Cross-section convergence $\left(10^{-4} \mathrm{~s}^{-1}\right)$

Fig. 13. Cross-section of $u$ and $w$ winds $\left(\mathrm{m} \mathrm{s}^{-1}\right)$, and their convergence $\left(10^{-4} \mathrm{~s}^{-1}\right)$ at $12 \mathrm{Z} 26 \mathrm{July}$.

at $0900 \mathrm{Z}$ on 26 July. Figure 16a shows that without TRMM SST, both the F0 and F2 simulations have their convergence centers northeast of Mumbai, and no convergence is seen near the urban center. The F1 simulation, with SST and no urban model, has a convergence belt along the coastal region, while its center is to the south of Mumbai. With the urban model (F2 simulation), the convergence zone narrows and strengthens over the Mumbai peninsula. 

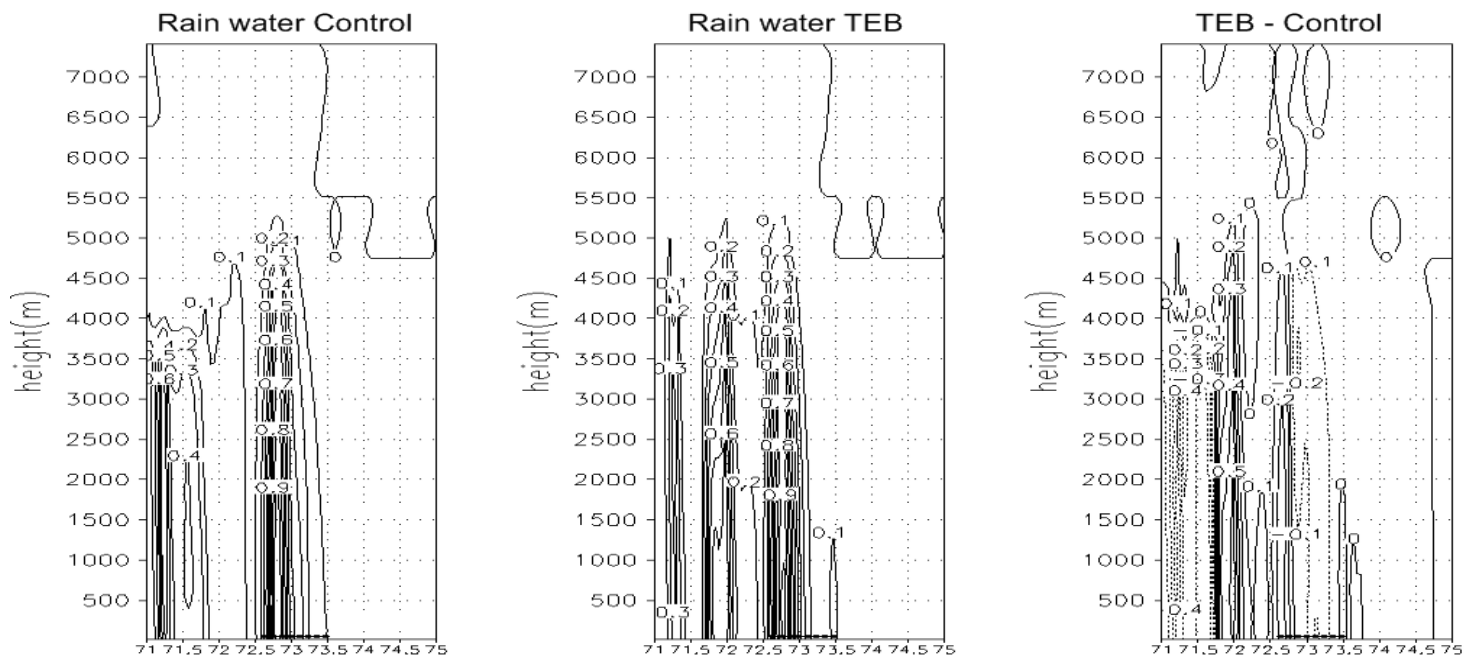

Fig. 14. Cross-section of rainwater mixing ratio $\left(\mathrm{g} \mathrm{kg}^{-1}\right)$ at $19.15 \mathrm{~N}$ from $71 \mathrm{E}$ to $75 \mathrm{E}$ at $12 \mathrm{Z} 26 \mathrm{July}$.
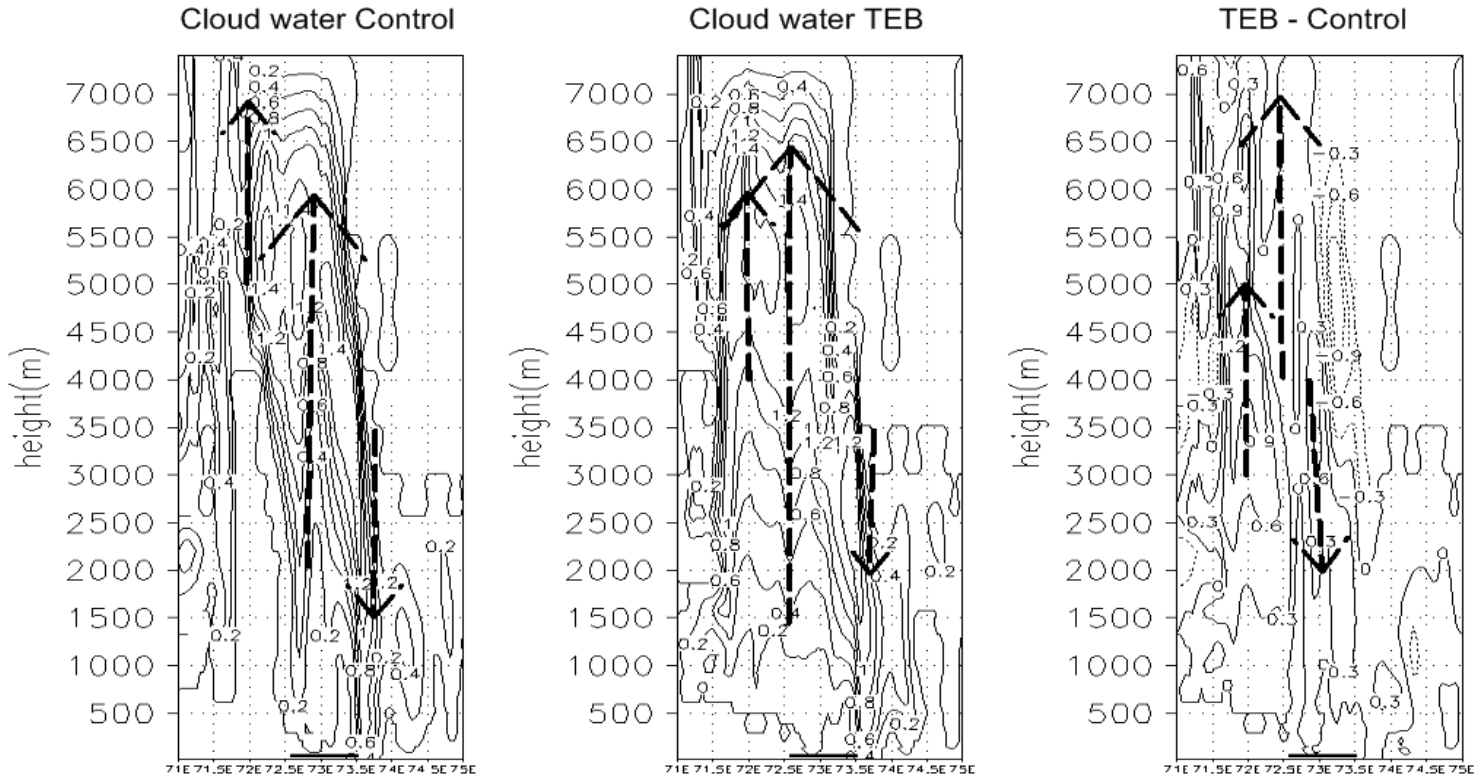

Fig. 15. Cross-section of cloud water mixing ratio $\left(\mathrm{g} \mathrm{kg}^{-1}\right)$ at $12 \mathrm{Z} 26 \mathrm{July}$. Arrows show the location of updrafts and downdrafts.

Figure $16 \mathrm{~b}$ shows the explicit contribution of each effect. The spatial plot suggests that the updated SST fields have an important effect on convergence and rainfall. Interaction of the urban scheme and the TRMM SST allows for more realistic local scale heterogeneities to be developed that alters the location of the rainfall bands. Figure 16c shows the vertical convergence structure at $19.15^{\circ} \mathrm{N}$. Adding the TRMM SST field (f1) increases the strength of the convergence at the border, but decreases the convergence above the Mumbai region, and without the SST, the urban model (f2) decreases the convergence slightly above the urban area. However, their interactions show an obvious increasing effect on the convergence above the city. Vertical velocity shows a similar effect (not shown). Without the TRMM SST data, the updraft located to the east of the city in the urban model weakens. The TRMM SST thus appears to provide the right gradients that displaced the updraft zone to the east of the city, and the urban model strengthens the upward motion of the air mass.

The resulting impact on the accumulated rainfall is shown in Fig. 17. The rainfall simulation is enhanced due to the TRMM SST (F1). The simulated locale is northeast of Mumbai. The urban model leads to changes that locate the heavy 

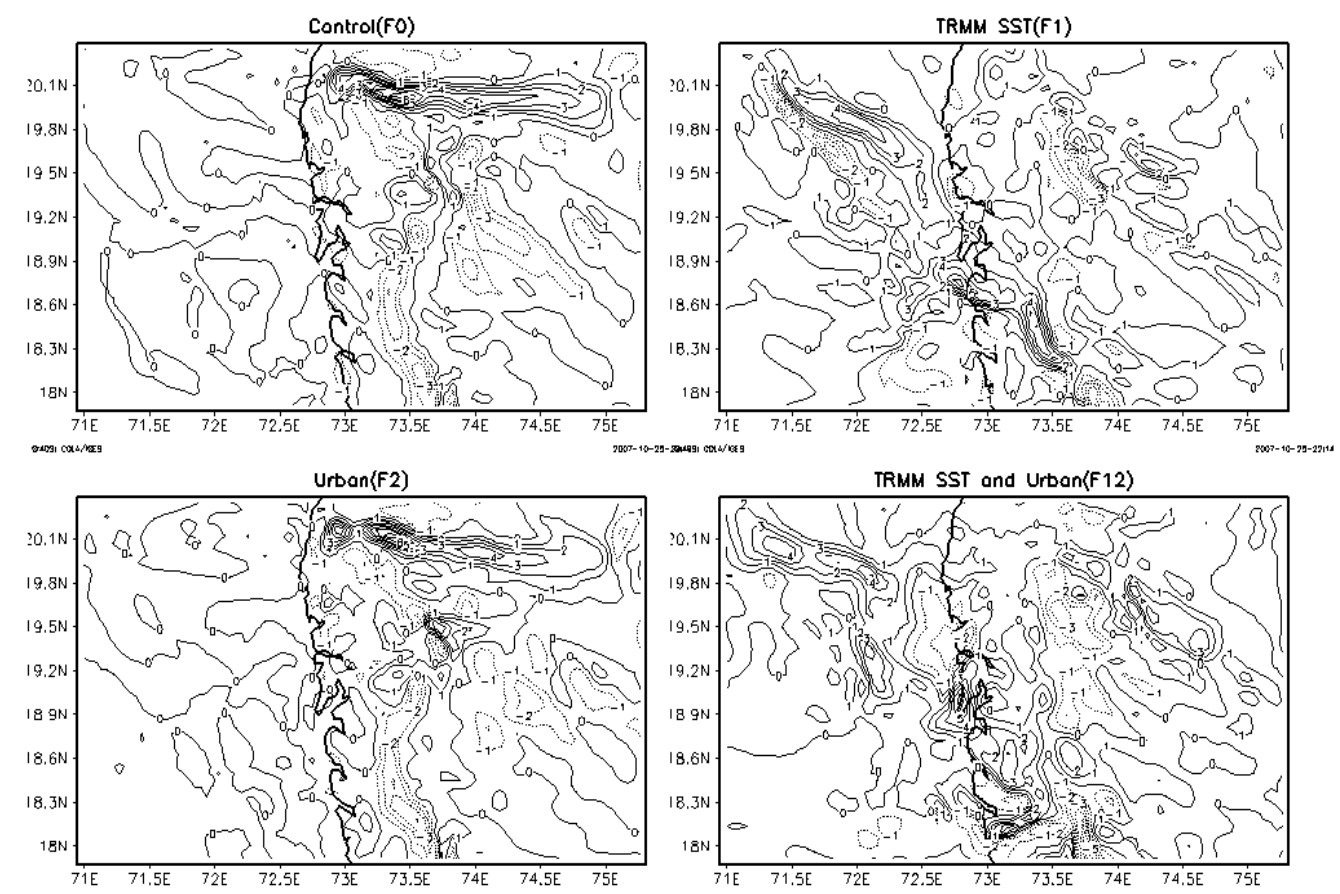

(a)
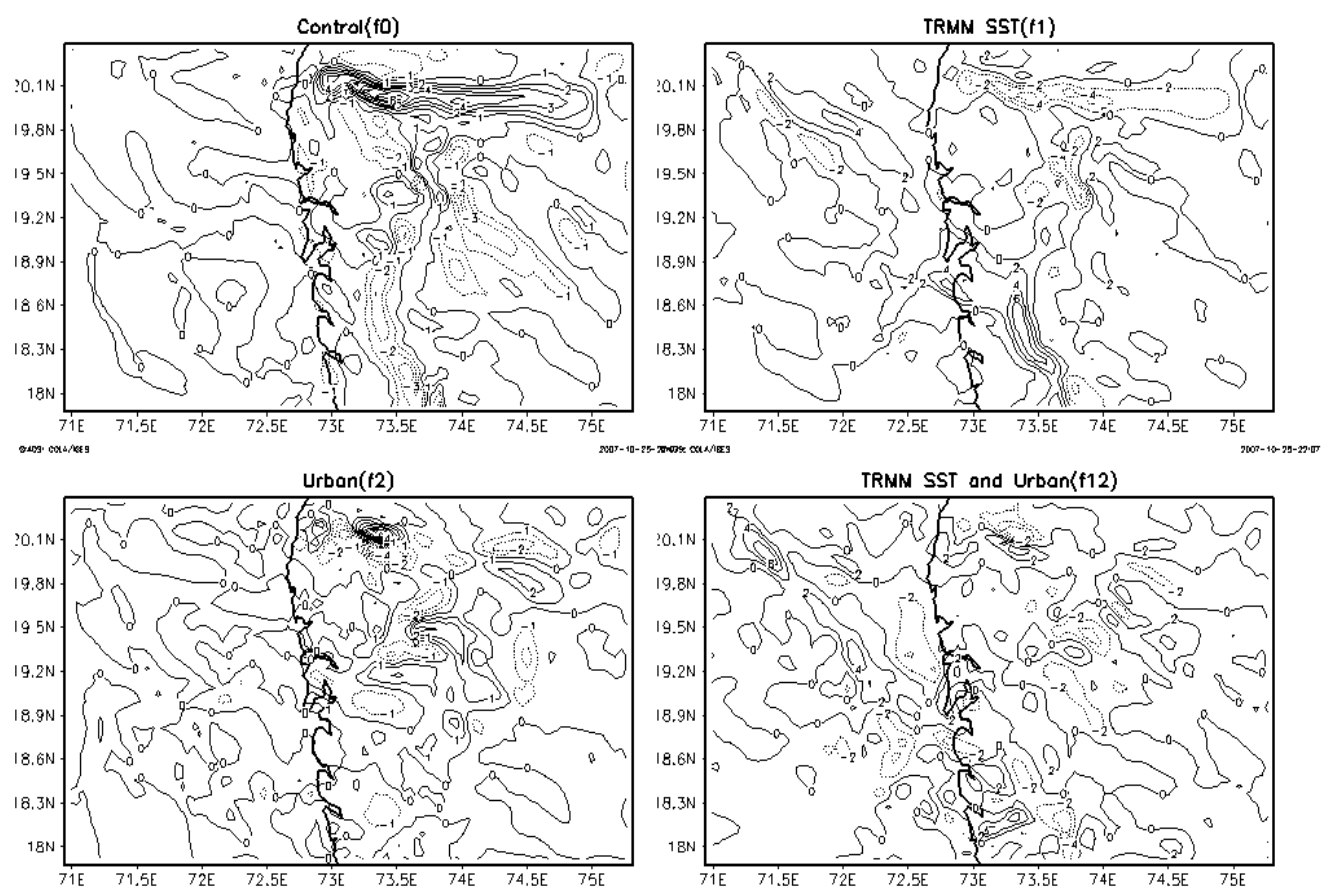

(b)

Fig. 16. Simulated convergences $\left(10^{-4} \mathrm{~s}^{-1}\right)$ at $9 \mathrm{Z} 26$ July. (a). Model simulations: control, TRMM SST, urban, TRMM SST and urban. (b) Factor separation analyzed values of individual and interaction effects. Positive values (solid contours) represent areas of positive change in convergence, and negative values (dashed contours) represent areas of negative change in convergence. $\mathrm{f} 12=\mathrm{F} 12-(\mathrm{F} 1+\mathrm{F} 2)+\mathrm{F} 0(\mathbf{c}) \mathrm{Same}$ as (b) but for cross section at $19.15 \mathrm{~N}$. 

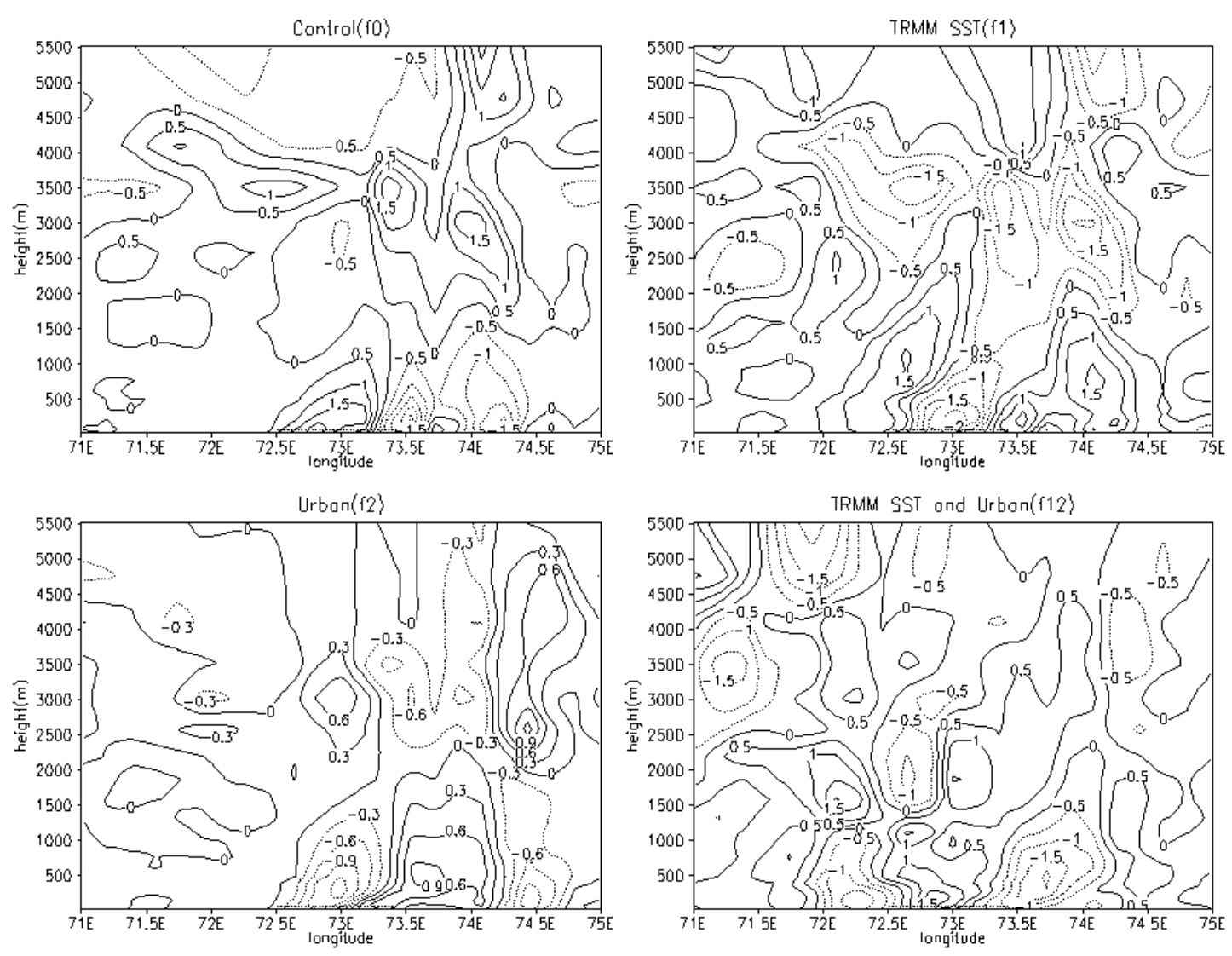

(c)

Fig. 16. Continued.

precipitation center above Mumbai, and slightly west of the observation center (F12).

On 27 and 28 July, the simulation showed the same trends as 26 July. Figure 18 shows the time series and location of the individual simulations and interactions based on the factor separation analysis. Summarizing these results, the urban model by itself did not affect the precipitation pattern over the region. However, considered in conjunction with realistic SSTs, the urban model creates the right mesoscale boundaries that contribute to significantly increase rainfall over Mumbai. This interaction effect contributes to over $200 \mathrm{~mm}$ of the precipitation for this event, especially during the maximum intensity of this precipitation event.

\section{Conclusions}

We simulated the 26 July 2005 exceptional heavy rain event in Mumbai using a mesoscale model (RAMS) coupled with an explicit urban energy balance scheme (the TEB). The following conclusions can be made:

1. The mesoscale model, RAMS, had a reasonably good performance in simulating the precipitation fields when

using proper schemes and reliable initial and boundary conditions.

2. Coupling the explicit urban model showed a consistently enhanced performance.

3. The urban landscape caused an urban heat island. The urban effects interacted with the SSTs causing a mesoscale convergence zone over Mumbai. This convergence zone appears to be a major reason for the moisture transport and heavy rain to center over Mumbai.

4. The factor separation analysis suggests that the urban landscape by itself is not the main reason for the enhanced rainfall; rather the combination of the updated SST fields using the TRMM data, and the urban effects simulated by the TEB/urban model that created the realistic gradients that accurately maintained the convergence zone over Mumbai.

In summary, the SSTs and landscape pattern helped transport large amounts of moisture over the western Ghats region, while the mesoscale boundaries created by the urban land surface and sea surface temperature gradients helped the 

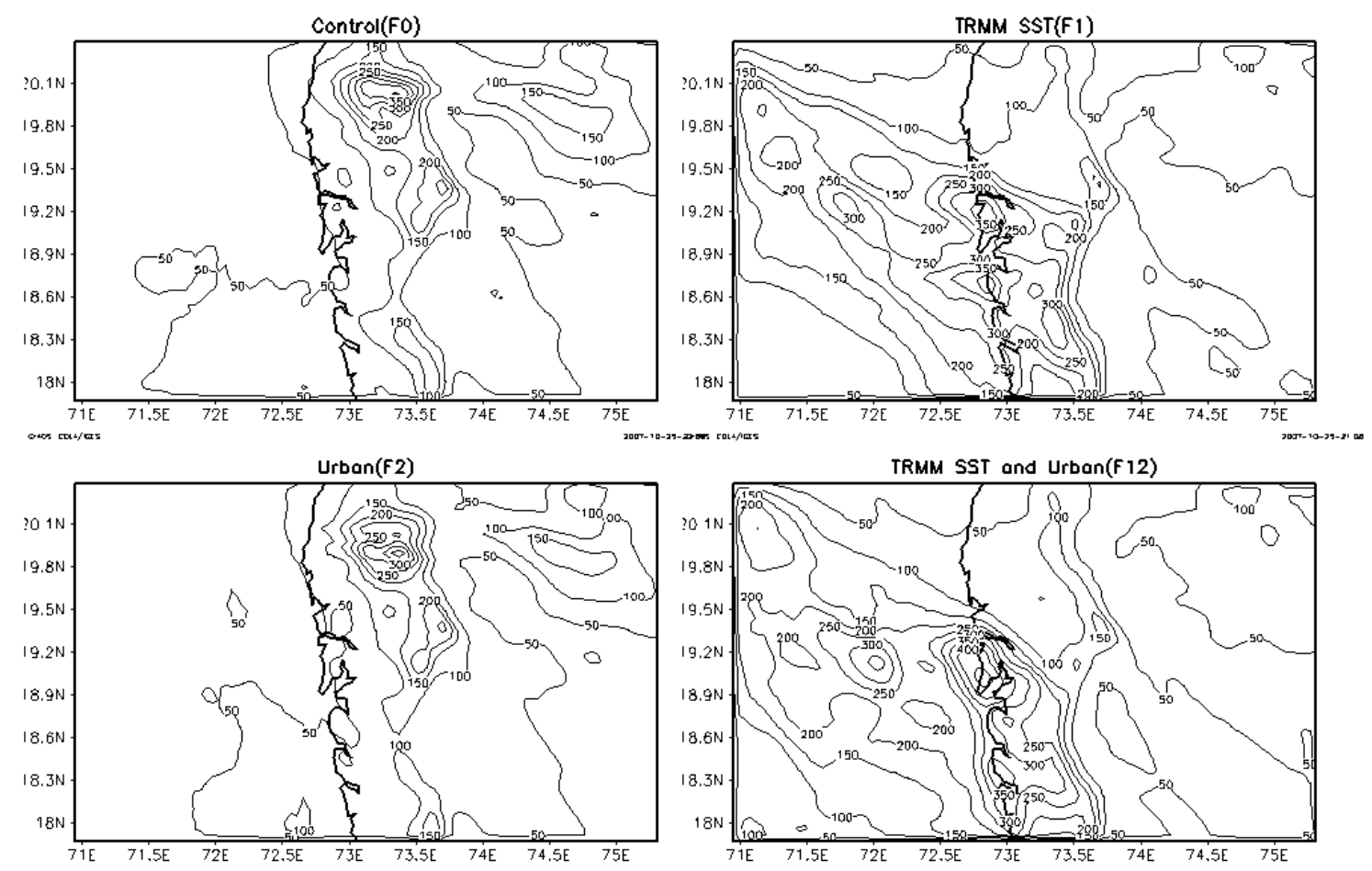

Fig. 17. Factor separation analysis for accumulated precipitation (mm).

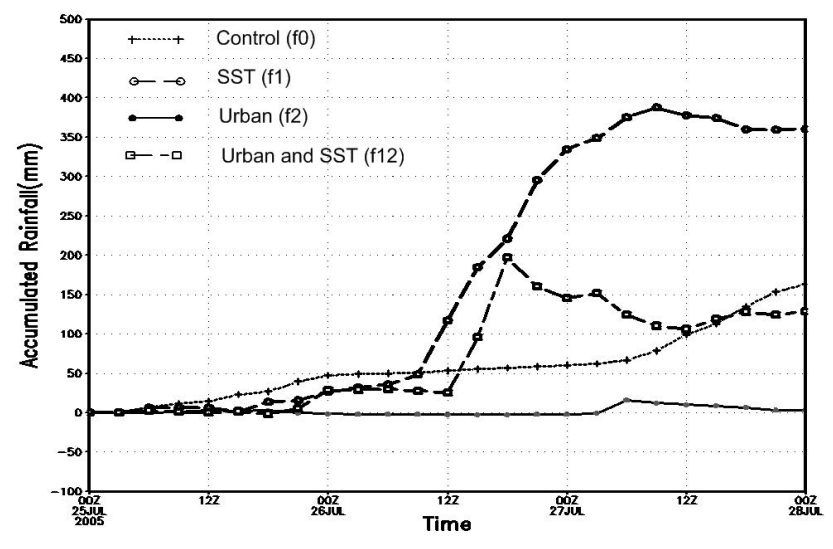

Fig. 18. Analysis of the accumulated precipitation (mm) over Santacruz airport: the control, the effect of TRMM SST, the effect of urban model and the effect of their interactions.

positioning by the convergence zone and heavy precipitation focus over Mumbai.

Acknowledgements. The authors would like to acknowledge NSF-ATM 0233780 (S. Nelson), NASA-THP (NNG05GQ47G, NNG06GH17G and NNX08AV80G J. Entin and B. Choudhury), NASA-IDS (NNG04GL61G J. Entin and G. Gutman), NASA LCLUC Program (G. Gutman). The study also benefited from the Purdue Asian Initiative Program. Roger A. Pielke, Sr. was also supported in part by the University of Colorado at Boulder (CIRES/ATOC) and NASA Grant NNX06AG74G.
Edited by: A. B. Guenther

\section{References}

Avissar, R. and Pielke, Sr., R. A.: A parameterization of heterogeneous land surfaces for atmospheric numerical models and its impact on regional meteorology, Mon. Weather Rev., 117, 21132136, 1989.

Bohra, A. K., Basu, S., Rajagopal, E. N., Iyengar, G. R., Gupta, M. D., Ashrit, R., and Athiyaman, B.: Heavy rainfall episode over Mumbai on 26 July 2005-Assessment of NWP guidance, Curr. Sci. India, 90, 1188-1194, 2006.

Bornstein, R. and Lin, Q.: Urban heat islands and summertime convective thunderstorms in Atlanta: three case studies, Atmos. Environ., 3, 507-516, 2000.

Braham, R. R. and Wilson, D.: Effects of St. Louis on Convective Cloud Heights, J. Appl. Meteorol., 17, 587-592, 1978.

Chang, H., Kumar, A., Niyogi, D., Mohanty, U. C., Chen, F., and Dudhia, J.: The role of land surface processes on the mesoscale simulation of the 26 July, 2005 heavy rain event over Mumbai, India, Global Planet. Change, in press, 2008.

Cotton, W. R., Pielke, Sr., R. A., Walko, R. L., Liston, G. E., Tremback, C. J., Jiang, H., McAnelly, R. L., Harrington, J. Y., Nicholls, M. E., Carrio, G. G., and McFadden, J. P.: RAMS 2001: 15 Current Status and Future Directions, Meteorol. Atmos. Phys., 82, 5-29, 2003. 
Deardorff, J.: Efficient prediction of ground surface temperature and moisture with inclusion of a layer of vegetation, J. Geophys. Res., 20, 1889-1903, 1978.

Dickinson, R. E.: Modelling evapotranspiration for threedimensional global climate models, Climate Processes and Climate Sensitivity, Geophys. Monogr., 29, 58-72, 1984.

Francis, P. A. and Gadgil, S.: Intense rainfall events over the west coast of India, Meteorol. Atmos. Phys., 94, 27-42, 2006.

Gero, A. F. and Pitman, A. J.: The Impact of Land Cover Change on a Simulated Storm Event in the Sydney Basin, J. Appl. Meteorol. Clim., 45, 283-300, 2006.

Goswami, B. N., Sengupta, V. D., Madhusoodanan, M. S., and Xavier, P. K.: Increasing Trend of Extreme Rain Events Over India in a Warming Environment, Science, 314, 1442-1445, 2006.

Holt, T., Niyogi, D., Chen, F., LeMone, M. A., Manning, K., and Qureshi, A. L.: Effect of Land- Atmosphere Interactions on the IHOP 24-25 May 2002 Convection Case, Mon. Weather Rev., 134, 113-133, 2006.

Howard, L.: The climate of London, deduced from meteorological observations, London, Harvey and Darton, 348 pp., 1833.

Jenamani, R. K., Bhan, S. C., and Kalsi, S. R.: Observational/forecasting aspects of the meteorological event that caused a record highest rainfall in Mumbai, Curr. Sci. India, 90, 13441363, 2006.

Johnson, G. T., Oke, T. R., Lyons, T. J., Steyn, D. G., Watson, I. D., and Voogt, J. A.: Simulation of Surface Urban Heat Islands Under "Ideal" Conditions at Night Part 1: Theory and Tests Against Field Data, Bound.-Lay. Meteorol., 56, 275-294, 1991.

Kalnay, E., Kanamitsu, M., Kistler, R., et al.: The NCEP/NCAR 40-year reanalysis project, B. Am. Meteorol. Soc., 77, 437-471, 1996.

Koster, R. D., Dirmeyer, P., Guo, Z., et al.: Regions of strong coupling between soil moisture and precipitation, Science, 305, 1138-1141, 2004.

Koster, R. D. and Suarez, M. J.: Energy and water balance calculations in the Mosaic LSM, NASA Tech. Memo., 104606, 9, 59 pp., 1996.

Kumar, A., Dudhia, J., Rotunno, R., Niyogi, D., and Mohanty, U. C.: Analysis of the 26 July 2005 heavy Rain event over Mumbai, India using the Weather Research and Forecasting (WRF) model, Q. J. Roy. Meteor. Soc., in press, 2008.

Kumar, V., Bhagat, D. K., Kumar, U. R., and Ganesh, M. S.: Impact of low level jet on heavy rainfall events over Mumbai, Mausam, 58, 229-240, 2007.

Lee, T. J.: The impact of vegetation on the atmospheric boundary layer and convective storms, Atmospheric Science Paper No. 509, Colorado State University, Fort Collins, CO, 137 pp., 1992.

Masson, V.: A physically-based scheme for the urban energy budget in atmospheric models, Bound.-Lay. Meteorol., 94, 357-397, 2000.

Mukhopadhyay, P., Sanjay, J., Cotton, W. R., and Singh, S. S.: Impact of surface meteorological observations on RAMS forecast of monsoon weather systems over the Indian region, Meteorol. Atmos. Phys., 90, 77-108, 2005.
Nair, U. S., Hjelmfelt, M. R., and Pielke, Sr., R. A.: Numerical Simulation of the 9-10 June Black Hills storm using CSU RAMS, Mon. Weather Rev., 125, 1753-1766, 1997.

NCDC: National Climatic Data Center-Climate of 2005 accessed at http://www.ncdc.noaa.gov/oa/climate/research/2005/ ann/events.html\#globe on 10 March 2007.

Niyogi, D., Holt, T., Zhong, S., Pyle, P. C., and Basara, J.: Urban and land surface effects on the 30 July 2003 mesoscale convective system event observed in the Southern Great Plains, J. Geophys. Res., 111, D19107, doi:10.1029/2005JD006746, 2006.

Oke, T. R.: Boundary Layer Climate, 2nd ed. Routledge, 290 pp., 1987.

Oke, T. R.: The Urban Energy Balance, Prog. Phys. Geog., 12, 471508, 1988.

Pielke, Sr., R. A., Cotton, W. R., Walko, R. L., Tremback, C. J., Lyons, W. A., Grasso, L. D., Nicholls, M. E., Moran, M. D., Wesley, D. A., Lee, T. J., and Copeland, J. H.: Comprehensive meteorological modeling system - RAMS, Meteorol. Atmos. Phys., 49, 69-91, 1992.

Pielke, Sr., R. A., Lee, T. J., Copeland, J. H., Eastman, J. L., Ziegler, C. L., and Finley, C. A.: Use of USGS-provided data to improve weather and climate simulations, Ecol. Appl., 7, 3-21, 1997.

Pyle, P., Niyogi, D., Arya, S. P., Shepherd, M., Chen, F., and Wolfe, B.: An Observational and Modeling-based Storm Climatology Assessment for the Indianapolis, urban region, J. Appl. Meteorol. Clim., accepted, 2008.

Rozoff, C. M., Cotton, W. R., and Adegoke, J. O.: Simulation of St. Louis, Missouri, Land Use Impacts on Thunderstorms, J. Appl. Meteorol., 42, 716-738, 2003.

Shepherd, J. M. and Burian, S. J.: Detection of Urban-Induced Rainfall Anomalies in a Major Coastal City, Earth Interactions, 7, 1-17, 2003.

Shepherd, J. M., Pierce, H., and Negri, A. J.: Rainfall Modification by Major Urban Areas: Observations from Spaceborne Rain Radar on the TRMM Satellite, J. Appl. Meteorol., 41, 689-701, 2002.

Shyamala, B. and Bhadram, C. V. V.: Impact of mesoscale-synoptic scale interactions on the Mumbai historical rain event during 2627 July 2005, Curr. Sci. India, 91, 12, 1649-1654, 2006.

Stein, U. and Alpert, P.: Factor separation in numerical simulations, J. Atmos. Sci., 50, 2107-2115, 1993.

Stensrud, D. J.: Importance of Low-Level Jets to Climate: A Review, J. Climate, 9, 1698-1711, 1996.

Thielen, J., Wobrock, W., Gadian, A., Mestayer, P. G., and Creutin, J. D.: The possible influence of urban surfaces on rainfall development: a sensitivity study in 2D in the meso- $\gamma$-scale, Atmos. Res., 54(1), 15-39, 2000.

Vaidya, S. S. and Kulkarni, D. R.: Simulation of heavy precipitation over Santacruz, Mumbai on 26 July 2005, using Mesoscale model, Meteorol. Atmos. Phys., 98, 55-66, 2006.

Walko, R. L., Band, L. E., Baron, J., Kittel, T. G. F., Lammers, R., Lee, T. J., Ojima, D., Pielke, Sr., R. A., Taylor, C., Tague, C., Tremback, C. J., and Vidale, P. J.: Coupled atmosphere biophysics hydrology models for environmental modeling, J. Appl. Meteorol., 39, 931-944, 2000. 